\title{
El poblado en altura de Topaín (segunda región, Chile): una residencia en la Tierra
}

\section{The hillfort of Topaín (2 ${ }^{\text {nd }}$ Region, Chile): A Residence on Earth}

\author{
Xurxo M. Ayán Vila \\ (Grupo de Investigación en Patrimonio Construido, Euskal Herriko Unibertsitatea/Universidad del País Vasco) \\ e-mail: jorgemiguel.ayan@ehu.es \\ Sonia García Rodríguez \\ (Grupo de Investigación en Patrimonio Construido, Euskal Herriko Unibertsitatea/Universidad del País Vasco). \\ e-mail: sonia.garciar@ehu.es
}

\begin{abstract}
RESUMEN
Este artículo aborda el estudio arqueológico del espacio doméstico del asentamiento de Topaín, ocupado durante la fase final del Período Intermedio Tardío (850-1470 A. D.). Desde la Arqueología del Paisaje y la Arqueología de la Arquitectura llevamos a cabo una relectura de la trama edificada del poblado, empleando como herramientas metodológicas el análisis formal y el análisis sintáctico del espacio. Nuestra interpretación hace hincapié en la existencia de un ordenamiento urbanístico y de toda una escenografía arquitectónica que obedece tanto a factores socioeconómicos (emergente división social) como a tradiciones culturales (culto a los ancestros y a los cerros tutelares).
\end{abstract}

Palabras clave: Atacama; Período Intermedio Tardío; Análisis sintáctico; Arqueología del espacio doméstico; Ecología Política.

\section{ABSTRACT}

This article embraces our archaeological research about domestic space of Topaín settlement. This village was occupied during the final phase of the Late Intermediate Period, before the arrival of Inka Empire (850-1470 A.D.). From Landscape Archaeology and Archaeology of Architecture, we conducted a reading of the built space of Topaín, using as methodological tools formal analysis and syntax analysis. Our interpretation emphasizes the existence of an urban planning and an architectural scene that reflects both socioeconomic factors (emerging social division) as cultural traditions (sacrifices and offerings to ancestors and sacred mountains).

Keywords: Atacama; Late Intermediate Period; syntax analysis; Archaeology of domestic space; Political Ecology.

Recibido: 19-05-2015. Aceptado: 11-08-2015.

Cómo citar este artículo / Citation

Ayán Vila, X. M. y García Rodríguez, S. 2015: "El poblado en altura de Topaín (segunda región, Chile): una residencia en la Tierra", Arqueología de la Arquitectura, 12: e035. doi: http://dx.doi.org/10.3989/arq.arqt.2015.126

\section{Copyright}

(c) 2015 CSIC. Este es un artículo de acceso abierto distribuido bajo los términos de la licencia Creative Commons Attribution-Non Commercial (by-nc) Spain 3.0. 
HAY ALGO DENSO, unido, sentado en el fondo, repitiendo su número, su señal idéntica. Cómo se nota que las piedras han tocado el tiempo, en su fina materia hay olor a edad, y el agua que trae el mar, de sal y sueño.

Pablo Neruda, Unidad (Residencia en la Tierra)

\section{ARQUEO-LOGÍA DE TOPAÍN O LA INSOPORTABLE LEVEDAD DE UN CERRO-ISLA}

Sin un cambio de actitud ante estos lugares prehistóricos cualquier intento comprensivo estará condenado al continuismo, o sea a seguir forzando el registro arqueológico para hacerlos compatibles con un modo de vida campesino primigenio que sólo existió en la mente de los arqueólogos.

(Márquez 2003: 270).

El presente artículo es un avance de resultados del trabajo que los autores hemos llevado a cabo en el marco del proyecto "Agriculture and Empire in the High Altitude Atacama", iniciativa desarrollada desde la Universidad de Chile, la Universidad de New Mexico (USA) y el Instituto de Ciencias del Patrimonio del CSIC. Este proyecto se centra en el análisis arqueológico de las diferentes economías políticas que se suceden en esta región desde el Período Intermedio Tardío (850-1470 A. D.) (de ahora en adelante PIT) hasta la llegada del imperio inka.
Este momento de la prehistoria regional ha sido tradicionalmente caracterizado por el surgimiento de distintas organizaciones sociopolíticas producto de la desintegración de los desarrollos Tiwanaku y Wari que se expandieron por distintos espacios de los Andes durante el período medio. Mientras en la costa andina este proceso va de la mano con la conformación de grandes entidades estatales como Chimú (Moore 1992), en tierras interiores este proceso se expresa en la proliferación de poblados

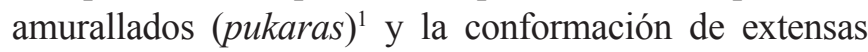
obras agrohidráulicas (Covey 2008; Troncoso 2015).

Nuestra participación en los trabajos de campo realizados en noviembre-diciembre de 2010 y julio de 2013 se centró en el estudio de la arquitectura y el espacio doméstico del poblado en altura de Topaín. Este yacimiento arqueológico se ubica en el alto Loa, en la región de Antofagasta, norte de Chile, concretamente en el interfluvio Loa-Salado (fig. 1). Esta zona, próxima a la ciudad minera de Calama, está experimentando en los últimos años un proceso de desertización demográfica, ya que la escasa población abandona paulatinamente el mundo rural y emigra a la ciudad. La presión de las compañías mineras del cobre y el modelo de gestión neoliberal de los recursos hídricos por parte del Gobierno chileno no hacen más que incentivar esta lucha estatal contra el hábitat disperso y los derechos de las comunidades locales (Tecklin, Bauer y Prieto 2013). La pequeña estancia cercana al pukara está abandonada

\footnotetext{
' La aparición de estos poblados amurallados sería un proceso contemporáneo a nivel regional en los Andes Centro Sur y datado hacia 1.250-1.300 d.C. (Covey 2008; Arkush 2008, 2011; Nielsen 2002).
}

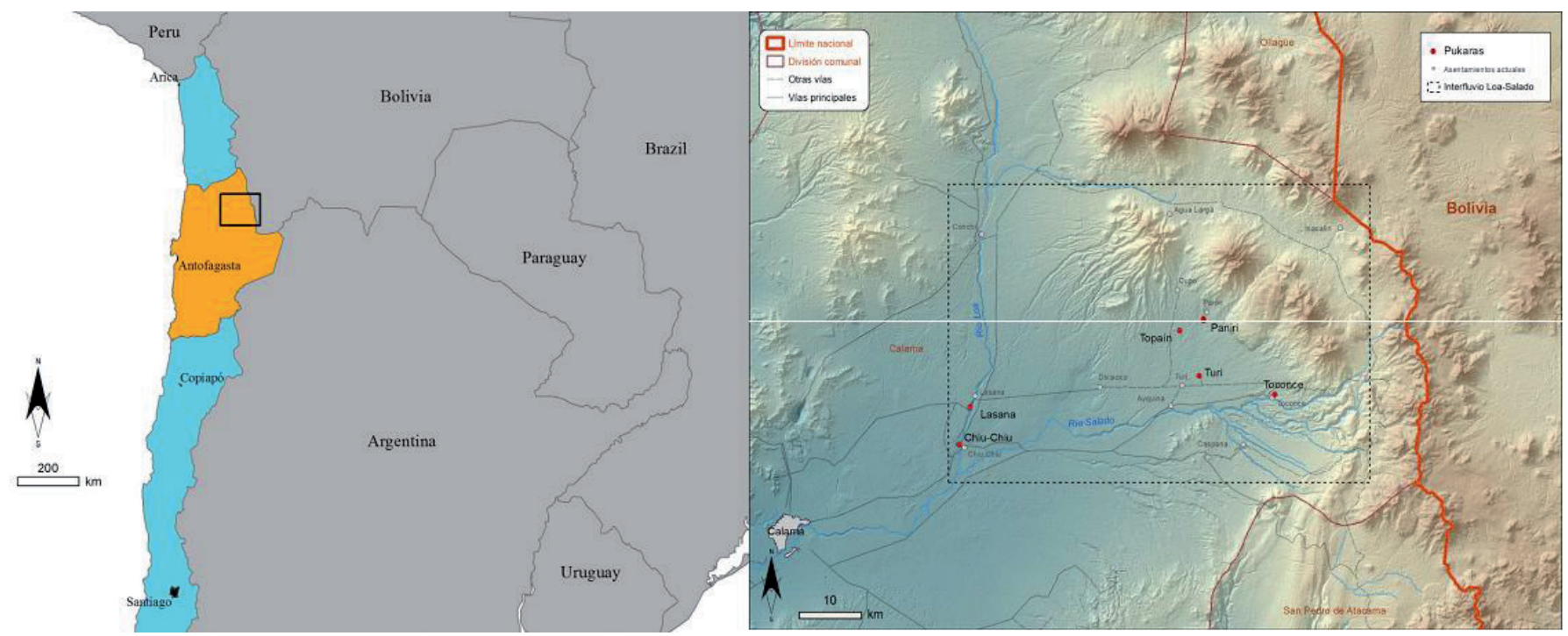

Figura 1. Ubicación del área de trabajo y principales poblados fortificados (pukara) citados en el texto. 
desde hace años, mientras que los pocos habitantes de la zona residen en pequeñas aldeas como Turi y Paniri. En la actualidad, la propiedad de Topaín es reivindicada por las comunidades indigenas atacameñas de Cupo y Ayquina-Turi. El interés estratégico del área de Topaín (Prieto y Ayán 2014) y su trasfondo simbólico como cerro sagrado se mantiene incólume en la actualidad.

La Arqueología del espacio doméstico por la que abogamos busca contribuir a recuperar el sentido de lugar de Topaín, respetando su naturaleza simbólica. A este respecto compartimos la filosofía llevada a la práctica en la década de 1980 por el grupo arqueológico Toconce (Castro, Berenguer y Aldunate 1979; Castro, Aldunate y Berenguer 1984; Aldunate y Castro 1981). Su enfoque etnohistórico y su respeto hacia la ritualidad local mostraban una ética de trabajo que abogaba por la integración de la comunidad local. El pago preceptivo a la Pachamama era una conditio sine qua non para iniciar las intervenciones arqueológicas. Nuestro equipo de trabajo ha pretendido hacer lo mismo, si bien cabe destacar que el contexto histórico es muy diferente, debido al proceso de empoderamiento patrimonial por parte de una comunidad indígena que tiene reconocimiento jurídico desde 1993. En esta nueva situación no contamos con permiso de los comuneros para realizar excavaciones, pero sí hemos podido elaborar planos, llevar a cabo una prospección intensiva (Parcero, Fábrega, García, Troncoso y Salazar 2012; Parcero, Fábrega, Ferro, Troncoso y Salazar 2013) y, en la campaña de julio de 2013, un análisis sintáctico del espacio.

Dentro de la metahistoria arqueológica de Topaín, nuestro trabajo continúa las meritorias aproximaciones llevadas a cabo en años precedentes por investigadores chilenos, entre los que destaca Simón Urbina (2010). Cabe señalar el esfuerzo de estos trabajos de campo, realizados siempre con escasos recursos y sin poder desplazar grandes equipamientos topográficos, como también ha sido en nuestro caso. Su investigación sobre la arquitectura formativa en la cuenca del Loa superior aporta un buen registro centrado en el análisis descriptivo de las formas arquitectónicas. Este tipo de trabajos se enmarca en una tradición funcionalista a partir de la cual se han generado modelos interpretativos del poblamiento a escala territorial. Dentro de estos patrones Topaín ha sido definido como pukara (Urbina 2007), 'sitio aglutinado' (Urbina 2010), 'aldea productiva' o 'asentamiento satélite' (Salazar 2013).

De acuerdo con este modelo, el poblamiento se articularía en el PIT a partir de tres tipos de asentamiento: pukaras, esto es, poblados fortificados, aldeas abiertas y pequeñas estancias. Todos estos recintos habitacionales estarían integrados por grupos familiares campesinos, artífices de la arquitectura hidráulica necesaria para maximizar los recursos agrícolas de las vegas, auténticos oasis en el desierto (Parcero, Fábrega, Ferro, Troncoso y Salazar 2013). Así mismo, parece fuera de toda duda la vinculación de estos espacios residenciales con rutas caravaneras por las que circularían diferentes grupos étnicos, mercancías, artefactos e ideas (Nielsen 1998-1999; Berenguer 2004; Pimentel 2008, 2009).

En comparación con los vecinos pukara de Paniri y Turi, el asentamiento de Topaín carece de muro perimetral, de necrópolis asociada y de arquitectura monumental, además de poseer un tamaño muy reducido. Quizás estas variables hayan incidido en su tradicional consideración como sitio aldeano menor (Urbina 2010: 130), asentamiento complementario en la red poblacional de la cuenca del río Salado o como aldea productiva orientada a la producción que garantizase la supervivencia de la población concentrada en asentamientos de mayor envergadura, como el cercano pukara de Turi (Salazar 2013). Como señala S. Urbina (2010: 129): "estas aldeas representan asentamientos satélites y especializados en alguna actividad productiva, agrícola en el caso de Talikuna, agrícola/ ganadera y minera en el caso de Topaín, ya que no se encuentran cementerios en sus proximidades inmediatas".

En nuestra opinión, creemos que este sugerente modelo debe ser contrastado a una escala más microespacial con el registro arqueológico disponible. Una herramienta para alcanzar este objetivo es la aplicación de un análisis arqueotectónico integral que nos permita alcanzar mínimamente la lógica social subyacente al entramado edificado del sitio de Topaín (fig. 2).

\section{ARQUEO-TECTURA DE TOPAÍN: ANÁLISIS FORMAL DE UN POBLADO EN ALTURA}

\author{
En las ciudades \\ Hablan \\ Hablan \\ Pero nadie dice nada. \\ La tierra desnuda aún rueda \\ $Y$ hasta las piedras gritan. \\ Vicente Huidobro, Las ciudades.
}

Desde la Arqueología del Paisaje y la Arqueología de la Arquitectura abordamos el estudio del espacio doméstico 


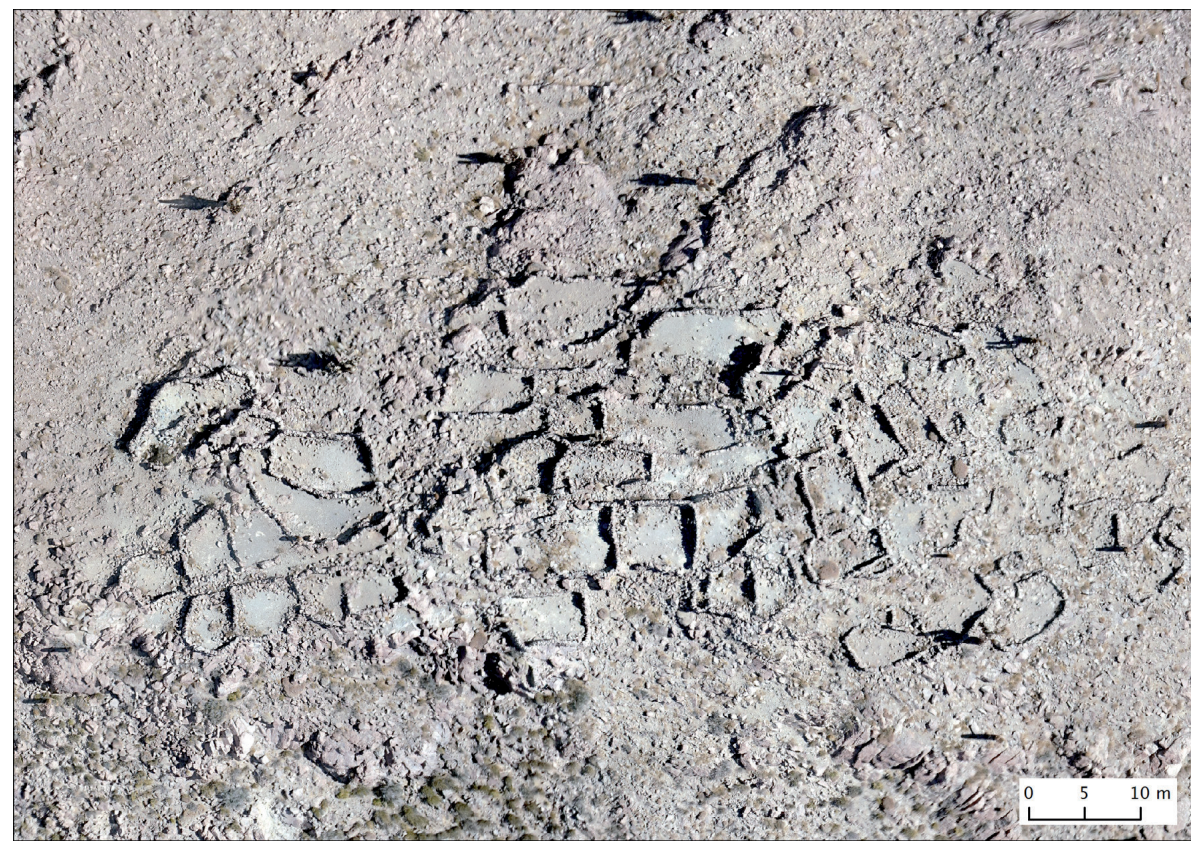

Figura 2. Ortoimagen producida por fotogrametría semiautomática a partir de fotografías de baja altitud tomadas con un drone del pukara de Topaín. de Topaín con la intención de complementar la imagen que nos aportan la arquitectura hidráulica y las áreas de captación de recursos, estudiadas por otros compañeros y compañeras en el marco del proyecto "Ecología Política de la Puna Atacameña"2. Esta aproximación a escala micro aplica un marco teórico-metodológico que hemos definido en trabajos precedentes (Mañana, Blanco y Ayán 2002) y que hemos aplicado hasta el momento en contextos europeos y africanos (González, Ayán, y Falquina 2009, 2013; Ayán 2012a, 2012b).

Desde estos presupuestos, el análisis arqueotectónico integral llevado a cabo en esta campaña de julio de 2013 abordó las siguientes actuaciones:

1. Análisis formal de las estructuras arquitectónicas, partiendo del trabajo de sistematización inicial llevado a cabo en la campaña de noviembre de 2010 (García Rodríguez 2011).

2. Análisis estratigráfico de paramentos murarios.

3. Registro de accesos y recorrido circulatorio por el interior del asentamiento.

\footnotetext{
${ }^{2}$ En el caso de Topaín, a día de hoy conocemos relativamente toda la red de irrigación establecida en el entorno inmediato del cerro. Las evidencias disponibles permiten ubicar la construcción y uso de este conjunto en época PIT, de manera genérica. La batería de dataciones radiocarbónicas define un abanico coherente pero muy amplio, entre 800-1400 cal. A D. (Parcero y Fábrega 2015). Esto es también coherente con la aparentemente escasa presencia de materiales más tardíos (inka). El sistema está espacialmente vinculado a un asentamiento nuclear estable. Lo esencial del sistema sería construido y usado en época preinka. No parece haber un uso en época incaica, al menos uno que sea significativo (Parcero, Fábrega, Ferro, Troncoso, Salazar y Hayashida 2014).
}

4. Análisis funcional: con un registro en planta de las áreas de actividad visibles en superficie. Así mismo, contrastamos esta información con los estudios elaborados anteriormente sobre los artefactos cerámicos recogidos en el interior de las estructuras arquitectónicas del asentamiento.

5. Análisis sintáctico del espacio doméstico.

6. Dibujo arqueológico en planta de tres de las unidades domésticas identificadas en el precedente análisis sintáctico.

7. Fotogrametría 3D de estructuras de carácter cultual del denominado sector C, empleando el programa AGISOFT.

La herramienta metodológica primordial de esta propuesta es el análisis formal (Blanton 1994; Ching 1995; Baker 1998; Criado 1999) centrado, para nuestro caso, en un nivel espacial concreto del paisaje agrario de Topaín como es la arquitectura de las unidades domésticas. Prioriza, por lo tanto, la configuración espacial concreta del registro arquitectónico, su patrón de emplazamiento en el espacio circundante, articulación interna, función social, condiciones de visibilidad y condiciones de visibilización, patrón de movimiento y accesibilidad. El análisis formal de todas y cada una de estas dimensiones nos permitirá establecer el patrón formal y seguidamente un modelo hipotético de la organización espacial propia de la arquitectura doméstica del sitio.

Los edificios - y su agrupación en asentamientosson los únicos artefactos de la cultura material que dan 
orden al espacio vacío, generando los patrones espaciales donde tienen lugar las relaciones entre las personas. Las construcciones no son otros objetos, simples signos y símbolos que reflejan la sociedad, sino transformaciones del espacio a través de objetos. Tienen, por lo tanto, unas características estructurantes, forman parte activa del elenco de actores que conforma la sociedad. Existe toda una lógica social del espacio, incluso en ese aparente desorden de casas apiñadas sin resquicio que reina en el interior de los poblados en altura como Topaín (fig. 3). El carácter estructurante de la realidad social que otorgamos al espacio construido es la idea básica a partir de la cual se ha desarrollado desde la década de 1970 el método de análisis espacial de asentamientos, desarrollado ampliamente por Bill Hillier y Julienne Hanson en su libro The social logic of space (1984).

Nuestro análisis arqueotectónico engloba dentro del análisis formal este análisis sintáctico del espacio, una herramienta útil para acceder a los significados discursivos de los entramados arquitectónicos (Hillier 1996: 305306) concebidos como signos de comunicación no verbal (en la línea de la gramática transformativa de Chomsky) susceptibles de ser registrados en su calidad de elementos articuladores de las relaciones sociales. Del mismo modo que la sintaxis lingüística estudia las relaciones de ordenamiento y jerarquía entre los distintos miembros de una oración (sin entrar en su contenido semántico concreto), la space syntax estudia las formas en las que se vinculan y organizan los espacios de un conjunto arquitectónico, tratando de inferir aquellos aspectos de la estructuración social que pudieron influir en su diseño. Este tipo de análisis partió de la necesidad acuciante de replantear el paradigma vigente en ese momento sobre el diseño arquitectónico, un paradigma que marginaba la relación existente entre vida social y organización espacial y que obviaba el hecho de que las decisiones arquitectónicas estratégicas sobre la forma construida y la organización espacial tenían consecuencias sociales. El espacio carecía de contenido social y la sociedad no poseía un contenido espacial (Hillier y Hanson 1984: xi). No obstante, mientras el estructuralismo léviestraussiano estudiaba la organización espacial, trataba el espacio como un producto de esquemas previos, de estructuras cognitivas preexistentes (¿existen las organizaciones duales?), con la sintaxis del espacio el equipo de Hillier busca la autonomía descriptiva: los modelos espaciales deben ser descritos y analizados en sus propios términos, al margen de asunciones y prejuicios, de meras agencias causales externas. El ordenamiento del espacio, la construcción del espacio edificado es un elemento más en la construcción del mundo material, un reflejo y un activador de la conducta social.

La incidencia de estas propuestas analíticas desarrolladas por Hillier y su equipo en el University College de Londres (Hillier 1973; Hillier y Leaman 1974; Hillier

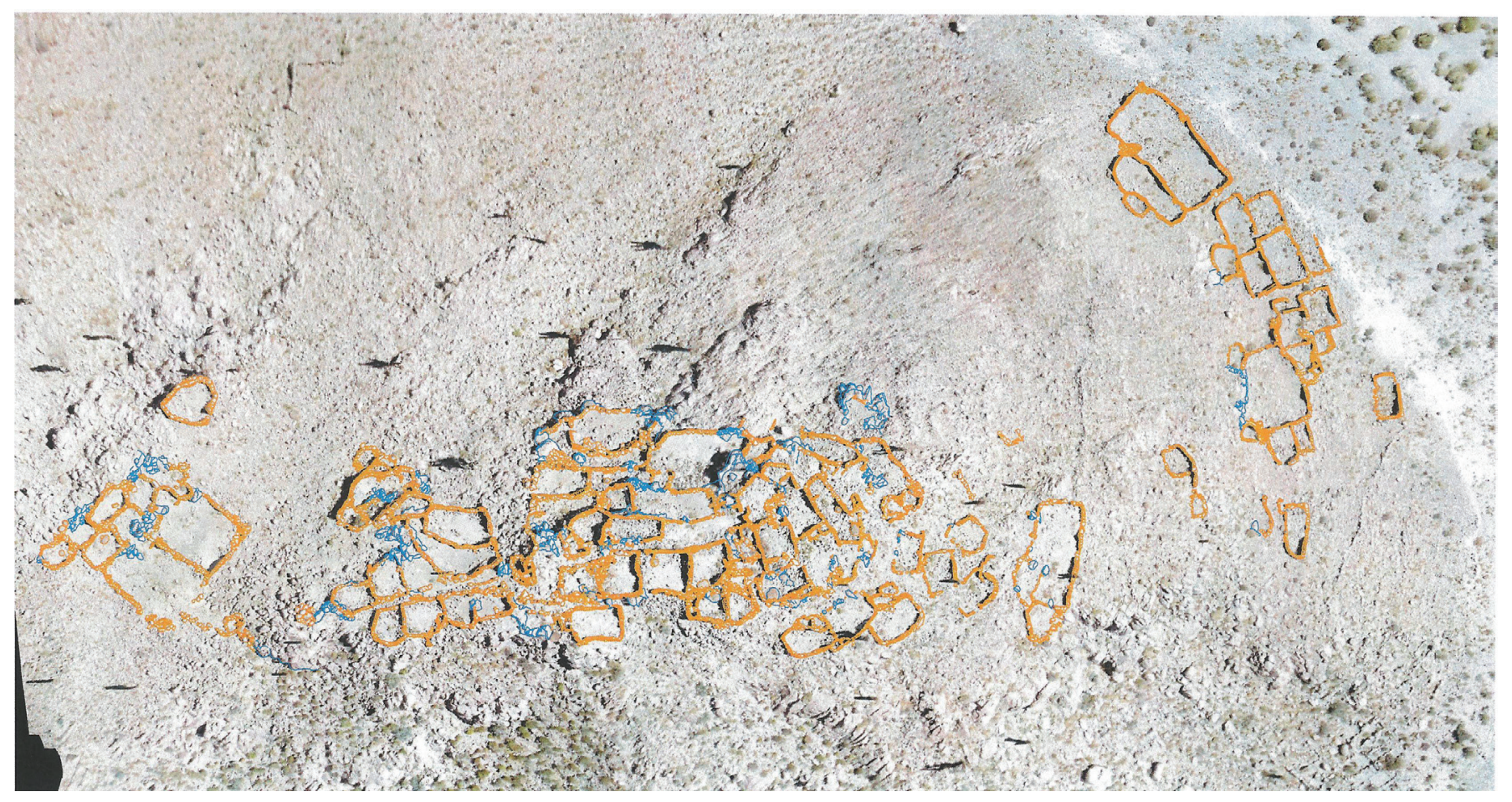

Figura 3. Planta del asentamiento de Topaín a partir de la ortoimagen de la figura 2. 
y Hanson 1984; Hillier, Burdett, Peponis y Penn 1987) ha sido notable desde comienzos de los 80 , alcanzando un notable desarrollo en las últimas dos décadas, debido en gran medida a tres factores (Dawson 2002: 471): a) la aplicación del análisis sintáctico del espacio a un conjunto más amplio de tipos de edificio de asentamiento; b) el desarrollo de software informático sofisticados que permiten una cuantificación precisa de las diferencias en la configuración espacial; 3) la organización de simposios internacionales sobre space syntax.

A todo ello añadiríamos la solidez teórica que sustenta estas analíticas y su capacidad para poner en evidencia las normas que rigen las relaciones sociales a través de un estudio de las formas. Unas formas y una configuración espacial que obedece a reglas y normativas que marcan los procesos de generación y crecimiento de los asentamientos. Pocas metodologías en Arqueología se han acercado tanto al ámbito del poder ideológico de las comunidades objeto de estudio (Chapman 1990: 57). Así mismo, contribuyen a conciliar teoría y práctica, ya que la arquitectura doméstica reactualiza los principios reguladores de una sociedad a través del uso de un espacio doméstico, dinámico, cambiante y en constante transformación.

Como consecuencia de estas potencialidades del análisis sintáctico ${ }^{3}$ contamos hoy en día con un notable número de trabajos publicados que aplican estas metodologías de análisis de entramados urbanos (Sánchez 1998; Shapiro 1999; Grahame 2000; Van Dyke 1999; Dawson 2002; Funari y Zarankin 2003; Jiménez 2005; Arenas 2007 entre otros). Para el área andina contamos con un reciente trabajo centrado en la arquitectura del valle del Colca (Perú) (Wernke 2012). A este respecto, cabe destacar que en nuestra área de trabajo atacameña es ésta la primera vez que se aplica este tipo de analíticas a registros prehispánicos.

\section{Cadena técnico-operativa de la arquitectura doméstica}

La arquitectura es una herramienta de construcción de la realidad social, toda una tecnología cultural que

\footnotetext{
${ }^{3}$ Cabe destacar que el reconocimiento unánime de la potencialidad del análisis sintáctico del espacio se acompañó también, desde un principio, de acertadas críticas sobre los presupuestos teóricos de partida, sobre su presunta validez y aplicabilidad universal, así como sobre el salto interpretativo que conlleva la ecuación organización espacial=organización social. Obviamente no es éste el sitio para desarrollar una crítica al método; para ello, véanse las reflexiones de Leach (1976), Yiannoli y Mithen 1986), Brown (1990b), Bradley (1993), Van Dyke (1999), Grahame (2000), Yaeger y Canuto (2000), Boyd (2007) o Bermejo (2009).
}

obedece al patrón de racionalidad de una comunidad concreta. Desde la captación de materias primas hasta el producto final, la construcción obedece a una cadena técnico operativa en la que ocupan su papel tanto los condicionantes medioambientales como las decisiones culturales (Lemonnier 1986, 1991; Cobas y Prieto 2001). Partiendo de esta base podemos definir el espacio construido en el cerro de Topaín como una 'arquitectura orgánica', que toma como referente la propia orografía de un elemento fisiográfico de hondo trasfondo simbólico para aquellas comunidades. En este sentido, cabe destacar que no se documentan materiales constructivos alóctonos. El propio cerro sirvió de cantera natural para la extracción de la toba volcánica empleada en la arquitectura doméstica.

A este respecto, la gran estructura abierta del sector A (10S013) es la única del asentamiento en la que podemos ver un frente de explotación de las entrañas líticas del cerro. La labor de devastado ha dejado a la luz una pared natural que se ha amortizado para maximizar su potencialidad como escenografía arquitectónica. La misma labor se documenta en las laderas del monte, en donde también se pudieron reutilizar cascotes desgajados por procesos de alteración (erosión, cambio brusco de temperaturas) y postdeposicionales. Cuatro son los tipos de materiales líticos utilizados:

- Grandes bloques ciclópeos para asentar la base de determinados muros.

- Mampuestos de tamaño medio para los paramentos murarios de las unidades domésticas, estructuras de almacenaje y tipo chullpa ${ }^{4}$.

- Pequeños cascotes, utilizados sobre todo en el entramado que conforma las terrazas de cultivo y muros de contención de plataformas habitacionales y caminos.

- Pequeños cascajos empleados como ripios en los paramentos murarios de mayor calidad.

A diferencia de otros ejemplos vecinos, como en la fase incaica de Turi (Castro y Cornejo 1990; Castro,

\footnotetext{
${ }^{4}$ Estas estructuras arquitectónicas de carácter ritual (torreones con vano a media altura del muro) son características de los grupos culturales del altiplano boliviano y parecen vincularse con una doble funcionalidad que vinculan fertilidad y ancestros: ofrendatorio a los muertos y lugar de almacenaje (Berenguer 2004; González 2014). Su presencia en el Loa Superior (Toconce, Likan) se ha considerado un indicador histórico cultural de la presencia física de las gentes del altiplano Castro, Aldunate y Berenguer 1984; Aldunate y Castro 1981) o, al menos, de la interacción de las comunidades locales con ellas.
} 
Maldonado y Vázquez 1993; Murphy 2015), aquí no observamos una utilización intencional de determinadas piedras en función de su textura, color o condiciones lumínicas. Por el contrario, documentamos una estrategia constructiva que discrimina materiales en función del tamaño. Así pues, las grandes viviendas adoptan el aparejo ciclópeo para monumentalizar los esquinales, los tramos de muro que dan a caminos públicos o los paramentos con buenas condiciones de visibilización desde cotas bajas del asentamiento. A este respecto, se constata una voluntad clara de construir de una determinada manera sin estar condicionada por limitaciones tecnológicas. Son decisiones conscientes las que llevan, por ejemplo, a pulir el acabado únicamente de las jambas de las puertas de acceso al interior de las construcciones o el remate de los deflectores que controlan el acceso y la visibilidad en la entrada a determinadas unidades domésticas.

Como decíamos, estamos ante una arquitectura orgánica que da lugar a escenografías que se integran perfectamente en el propio cerro, como una continuación del sustrato rocoso. Este efecto se realza con la ausencia total de cimentaciones. Un magnífico ejemplo es la estructura cultual 10S089 asociada a la unidad doméstica 10S090. Las construcciones se asientan directamente sobre la roca, conformando en ocasiones un continuum que impide diferenciar de lejos el entramado edificado del espacio natural. Esta circunstancia se da sobre todo en la arquitectura doméstica emplazada en las laderas SE y SW. Pero también es una constante en las estructuras aéreas tipo chullpa, dispuestas siempre sobre el roquedo para realzar su presencia y sus condiciones de visibilización ${ }^{5}$. Esta arquitectura nos remite a una relación estrecha entre espacio construido y solar ${ }^{6}$, algo común en los espacios sacrales que son habitados, como los santuarios de la Grecia clásica por poner un ejemplo conocido por todos. Pero también puede ser interpretada como una estrategia poliercética intencional. No olvidemos que Topaín no es en puridad un pukara ya que carece de muro perimetral. Sí es, en cambio, un poblado en altura que maximiza las condiciones naturales de defensa y su óptima situación

\footnotetext{
$\overline{5}$ Esta característica se repite sistemáticamente en el gran asentamiento de Turi, en donde las chullpas siempre se asientan sobre muros previos o sobre la roca natural (González 2015).

${ }^{6}$ Como señalan Castro y Aldunate (2003: 78) la sacralidad de los cerros integra a otros elementos naturales, como la fauna y la flora, cuya importancia se incrementa en función de la altura. Todas las plantas y animales que tienen una especial relevancia simbólica, nacen o proceden de los cerros. Del mismo modo creemos que actúa la arquitectura en cerros sagrados como el de Topaín.
}

para ver y ser visto. En este contexto, las vías de circulación a media ladera, prácticamente laberínticas, o el propio paramento murario exterior de las estructuras son elementos defensivos per se.

Dentro de la cadena técnica seguida por la comunidad (o comunidades) que construyó Topaín, la selección de la materia prima se hace en función del tipo de estructura a realizar. En este sentido, se constata todo un modelo diferenciado en la mampostería, dependiendo si se utiliza la piedra para aterrazamientos o estructuras habitacionales. A este respecto, se emplea la misma técnica constructiva (mampostería a hueso de cascote de pequeño tamaño) tanto en las terrazas de cultivo como en los muros de contención de los espacios habitados y de las vías de circulación. En ambos casos estamos ante una materialidad generada necesariamente por el trabajo colectivo. Mover grandes bloques líticos o habilitar una superficie plana en la pendiente del cerro Topaín nos remite a una colaboración entre individuos. En la figura 4 podemos ver las diferentes terrazas identificadas por nosotros. Esta verdadera arquitectura fundacional nos plantea cuestiones interesantes para intentar dilucidar la estructura social de esta comunidad: ¿cada terraza habitacional o cada terraza de cultivo es erigida por una unidad doméstica, por una familia, o todos los miembros colaboran solidariamente en su construcción? ¿Esas estructuras son usufructuadas como vivienda o campo de cultivo por cada unidad doméstica o estamos delante de un modo de producción doméstico (Sahlins 1972) sin diferencia ni relación alguna con la estructura de parentesco? ¿Es la consecuencia de un vínculo comunitario o del Poder ejercido por una élite local en un marco de división social? Como veremos más abajo, el análisis sintáctico nos permitirá calibrar estas hipótesis. En todo caso, resulta bastante clara la existencia de una planificación urbanística previa, materializada en la construcción de terrazas habitacionales en función de estimaciones previas en relación a la superficie disponible por cada unidad doméstica (fig. 4).

Esta mampostería empleada tanto en terrazas como viviendas o estructuras cultuales carece totalmente de argamasa o mortero. Siempre se elabora en seco, a hueso; únicamente en algunos paramentos murarios con mejor acabado observamos la utilización de pequeños ripios como refuerzo para asentar las juntas. En ningún caso detectamos empleo de tapial o adobe, elementos diagnósticos de las fases de ocupación del período incaico (Castro, Maldonado y Vázquez 1993; Urbina 2010). Únicamente documentamos en el sector B el empleo de 
Terrazas de Cimentación
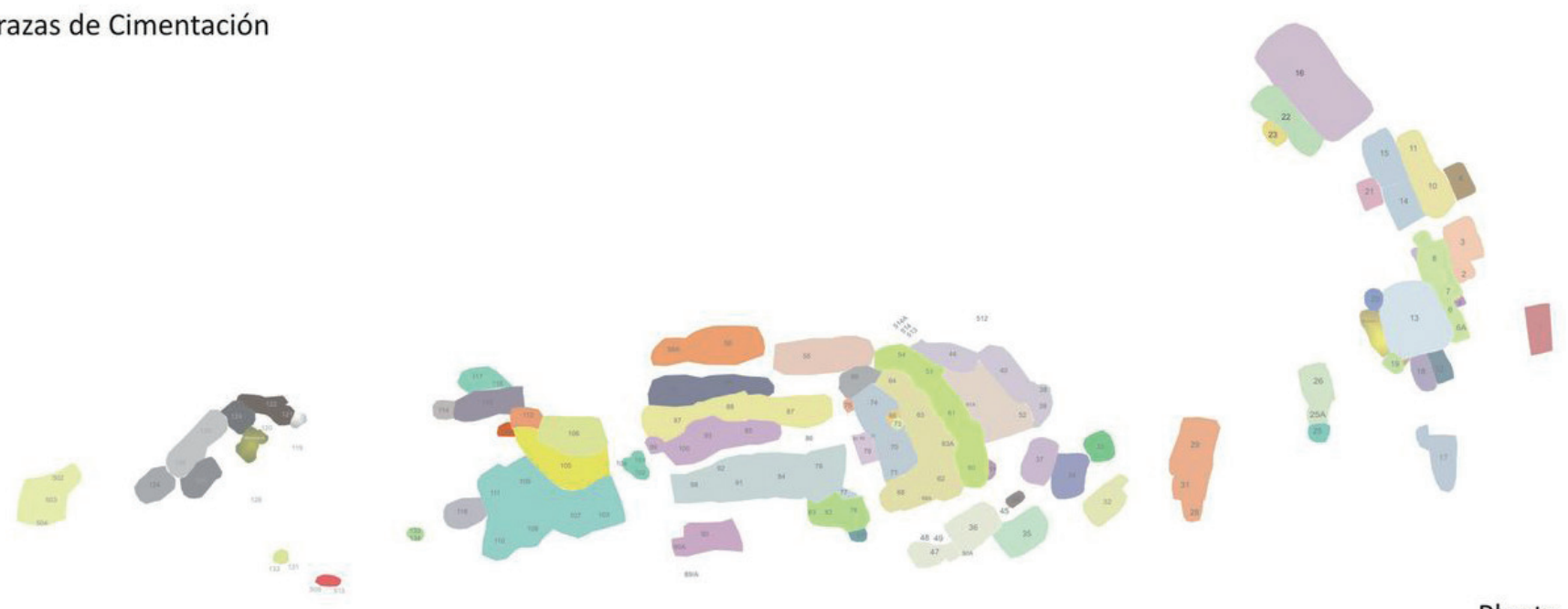

Planta

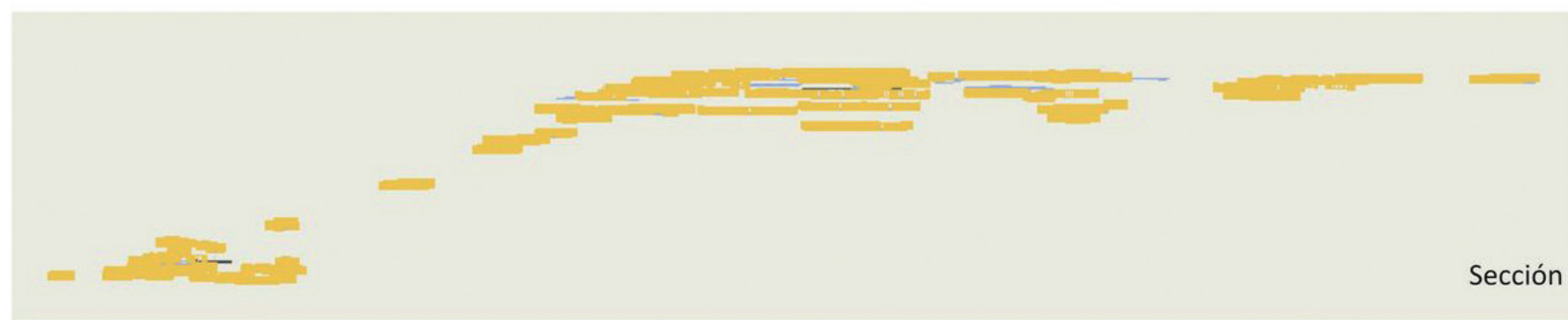

Figura 4. Identificación de las terrazas de cimentación habilitadas para asentar la trama edificada.

una suerte arena decantada con gravilla, de color amarillento, en las estructuras de almacenamiento registradas en la estancia 10S100 y en las estructuras cultuales 10S066, 10S073, así como en la estancia 10S053. Estas construcciones semisubterráneas se encuentran excavadas en el subsuelo y presentan este revestimiento térreo, en relación con cubiertas de falsa cúpula y pequeños ventanales de acceso ${ }^{7}$. Desde el punto de vista tipológico recuerdan un poco a las estructuras tipo troja o incluso al modelo de las qulqas incaicas.

En cuanto a los acabados de las estructuras y su sistema de cubierta poco podemos decir ante la falta de restos documentados en superficie, relacionados con el colapso y derrumbe de las construcciones. En este sentido, cabe llevar a cabo un estudio etnoarqueológico de la arquitectura doméstica tradicional en las vegas de Paniri, Turi y Topaín. En observaciones durante la campaña pudimos comprobar, en Ayquina y cabañas antiguas sobre el sitio arqueológico de Paniri,

\footnotetext{
${ }^{7}$ La toma de muestras sedimentológicas en la pared $\mathrm{S}$ del interior de la estructura abovedada tipo troja dentro de la ES10S093, permitió documentar evidencias polínicas de cultivos locales como maíz (Zea Mays) y quinoa (Chenopodium Quinoa) (Maldonado y Paredes 2015).
}

la utilización de la misma técnica constructiva que la empleada en el PIT para levantar las terrazas de cultivo y habitacionales. A su vez los accesos se realizan de la misma manera, con bloques careados a modo de jambas. A este respecto, teniendo en cuenta los condicionantes medioambientales, resulta plausible que se emplease también la misma técnica para la techumbre que en la arquitectura tradicional, con la utilización de madera de cactus y un entramado de paja de coirón y tepes de pasto. Se trataría de una cubierta plana ya que no documentamos evidencias de tejado a dos aguas, introducido por el Inka en la zona.

Desde el punto de vista de la cadena-técnica no observamos un uso diferenciado de recursos ni de saberes tecnológicos. Independientemente de su complejidad interna, todas las estructuras comparten una misma manera de hacer, de construir. El poblado de Topaín responde a un modelo arquitectónico evidente, aceptado por el colectivo, un estilo que es fruto de una tradición cultural respetada por la comunidad. La tradición es una garantía de la indivisión, un antídoto a la innovación y al cambio, un dispositivo que legitima la comunidad como totalidad autónoma y unidad homogénea. Las sociedades 
primitivas hacen gala de un conservadurismo intransigente, expresando en la incesante referencia al sistema tradicional de normas (Clastres 2001: 212). En relación con esto, la arquitectura doméstica de Topaín presenta las características definitorias de lo que algunos antropólogos han dado en llamar arquitectura primitiva (Guidoni 1989; Rapoport 1972). En este tipo de formaciones socioculturales - muy orientadas hacia las tradiciones - el proceso de diseño arquitectónico se basa en unos conocimientos técnicos que están al alcance de todos los integrantes de la comunidad, de ahí que cualquier miembro del grupo sea capaz de construir su propia vivienda. No obstante existe siempre un modelo preescrito que permite hacer o no hacer ciertas cosas, y que se ajusta a la mayor parte de las exigencias culturales, físicas y de mantenimiento (Rapoport 1972: 15-16). Este modelo es completamente uniforme, presenta muy pocas innovaciones y da lugar a una fuerte persistencia de la forma.

Siguiendo con nuestra argumentación, en las sociedades primitivas - e incluso en las campesinas tradicionales - la tradición cultural impone una disciplina o férreo control a la hora de construir la vivienda, configurando un modelo conocido por todos, lo que explica la ausencia de diseñadores o especialistas. Así mismo en estas comunidades no existe una diferenciación entre la magia y el trabajo, lo religioso y lo secular, el ritual y el uso del espacio; todas las manifestaciones de la cultura material reflejan de un modo u otro la cosmovisión aceptada y compartida por el colectivo. La cadena técnica que conduce a la arquitectura doméstica, la forma edificada, es una encarnación física de ese patrón de racionalidad, de esa tradición; el proceso de construcción de la vivienda, y las actividades cotidianas desarrolladas en su interior, expresan simbólicamente las bases ontológicas y metafóricas que articulan la particular cosmovisión de sus habitantes (Parker y Richards 1994b).

\section{Evolución del espacio doméstico. Análisis sintáctico}

\section{It is not any particular part of the building that matters,} but is overall relational form.

(Giddens 1984: 147).

The fundamental proposition of the syntax theory is not that there is a relation between settlement forms and social forces, but that there is a relation between the generators of settlement forms and social forces.

(Hillier y Hanson 1984: 82-83).
Desde las primeras referencias arqueológicas al sitio de Topaín (Pollard 1970) hasta los más recientes estudios sobre su arquitectura (Urbina 2007: 121-122; García Rodríguez 2011; Parcero, Fábrega, García, Troncoso y Salazar 2012) siempre se ha señalado la existencia de tres sectores de estructuras claramente individualizados: uno ubicado en la zona baja, al E sobre las terrazas de cultivo (sector A), un sector intermedio con construcciones a media ladera y sobre la cumbre allanada del primer alto (sector B) y un último sector que se desarrolla sobre una vaguada, con estructuras de carácter ritual asentadas sobre afloramientos rocosos y en relación con dos grandes espacios rectangulares (sector C). Aparentemente esta configuración del asentamiento podría responder a los condicionantes impuestos por la orografía. Sin embargo, la aplicación de un análisis sintáctico del espacio nos indica que estamos ante la materialidad generada por la propia metahistoria del sitio y ante un ordenamiento planificado que impuso una determinada lógica espacial y no otra (fig. 5).

En el caso del sector A podemos comprobar la existencia de un patrón de regularidad formal que se va a repetir en el sector B. El mapa de articulación axial nos permite individualizar tres conjuntos de estructuras separados por viales de circulación con una orientación NE-SW. La superposición del mapa axial y convexo deja entrever la presencia de tres nodos que canalizan la circulación, a modo de plazas o espacios abiertos (fig. 6). El primer conjunto parece corresponderse con lo que Urbina denomina estancia pastoril (Urbina 2010: 122). Destaca la presencia de una gran estructura rectangular con aparejo de mala calidad y acceso estrecho en el que no se constata ningún control de la visibilidad interior. Esta forma arquitectónica se identifica también en otras zonas de ladera del sector $\mathrm{B}$, siempre en relación a los senderos de entrada al poblado, en posición periférica $\mathrm{y}$ con acceso directo y rápido a los pastos y terrenos de cultivo. A su vez, suelen adosarse pequeñas estructuras a modo de chiquero. A su vez, la potencia de los derrumbes y la altura de los muros hacen pensar en que se traten de espacios abiertos sin techumbre. Esta materialidad sigue caracterizando los corrales de llamas en la arquitectura tradicional de la zona.

En el segundo conjunto, el análisis de accesos (fig. 6) nos lleva a individualizar dos unidades domésticas: la primera de ellas es una casa compleja conformada por tres estancias diferenciadas. La segunda es un tipo de vivienda que vamos a ver reproducido en el asentamiento 


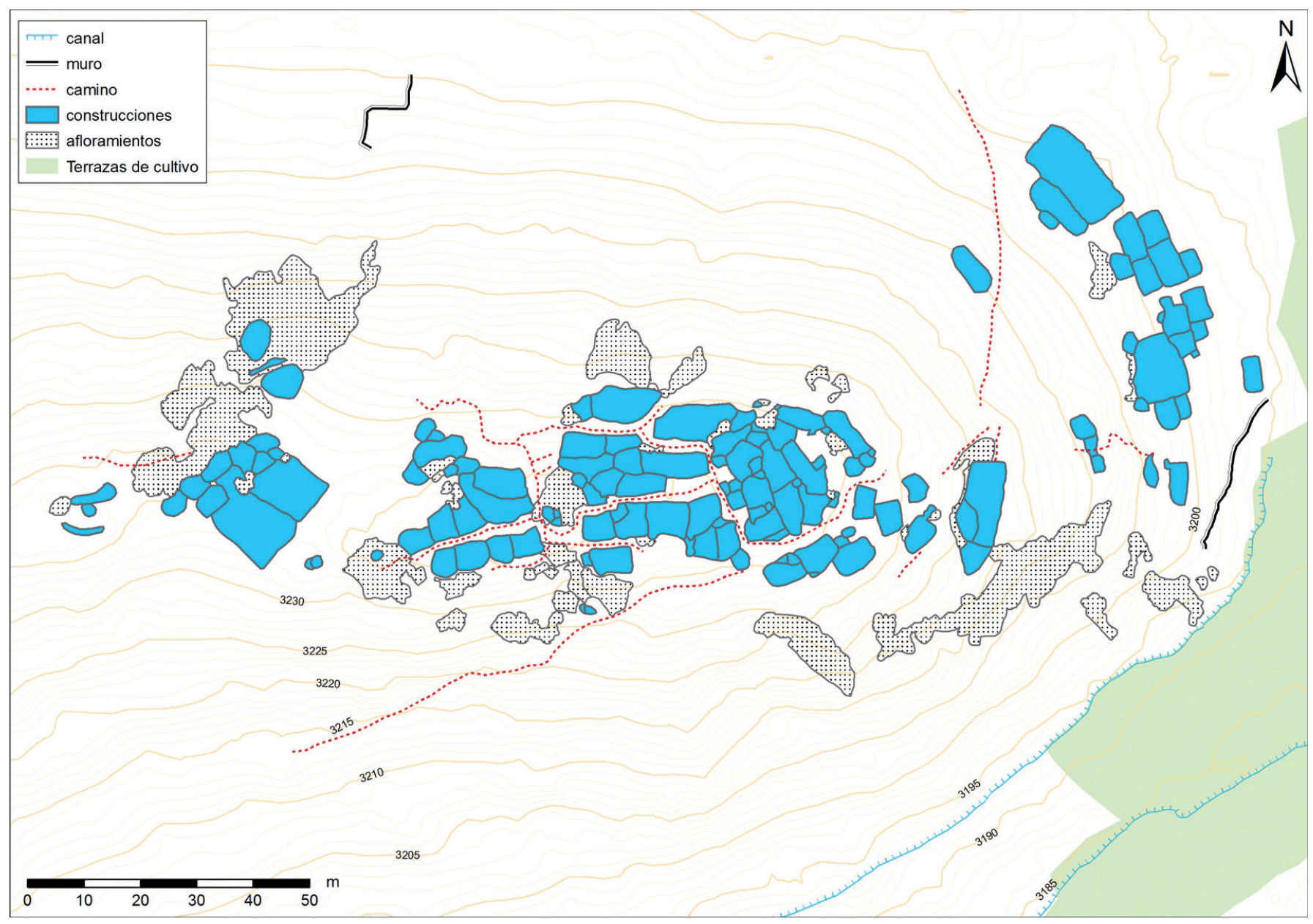

Figura 5. Identificación en planta de la trama edificada, principales vías de circulación y afloramientos rocosos.

en numerosas ocasiones: estructura de planta rectangular, con unas dimensiones de $8 \mathrm{~m} \mathrm{x} 3 \mathrm{~m}$, construida con mampostería. El acceso desde la calle se complementa con un nuevo filtro, un retranqueo generado por un muro transversal, a modo de deflector, que obliga al visitante a girar a la derecha, impidiéndole la visibilidad del espacio privado de la unidad doméstica. El interior de la estructura está formado por un único espacio multifuncional, sin subdivisiones internas. Esta impermeabilización del espacio doméstico podemos verla reflejada también en el tercer conjunto de habitación, incluso de una manera más sofisticada: el acceso desde la calle conlleva entrar en una suerte de recibidor (que en otros casos comparte espacio con un granero) desde donde se entra a la unidad doméstica. Desde la estancia principal se puede pasar a una última habitación a la que se adosa una estructura tipo chullpa con ventana interior. Este vano está orientado hacia los cerros de Chita y Q'aiqu, emplazados en dirección S. Por primera vez registramos una evidente estructura cultual formando parte de una vivienda compleja.
Teniendo en cuenta la estratigrafía muraria, esta unidad doméstica se asienta sobre una antigua terraza (aparejo de cascote menudo) relacionada con la gran estructura 10S013. Este espacio abierto, de grandes dimensiones, parece vertebrar toda esta zona del asentamiento. Como comentamos antes, aprovecha un frente de roca del cerro como pared $\mathrm{W}$ contribuyendo a la escenografía arquitectónica del conjunto del asentamiento, siendo bien visible desde la zona baja. Esta gran estructura tiene adosadas dos estructuras circulares con accesos bien definidos en las esquinas NW y SW; a su vez, el acceso desde el S se canaliza a través de una estructura ovoide con una puerta realmente monumental. Finalmente, la ES10S013 contaba con un acceso original (tapiado posteriormente) hacia el $\mathrm{E}$, que a través de una terraza conducía al exterior del asentamiento. La monumentalidad de la estructura y el hecho de contar con tres accesos diferenciados desde los nodos principales de circulación incrementan su notoriedad dentro del conjunto habitacional de este sector A. 

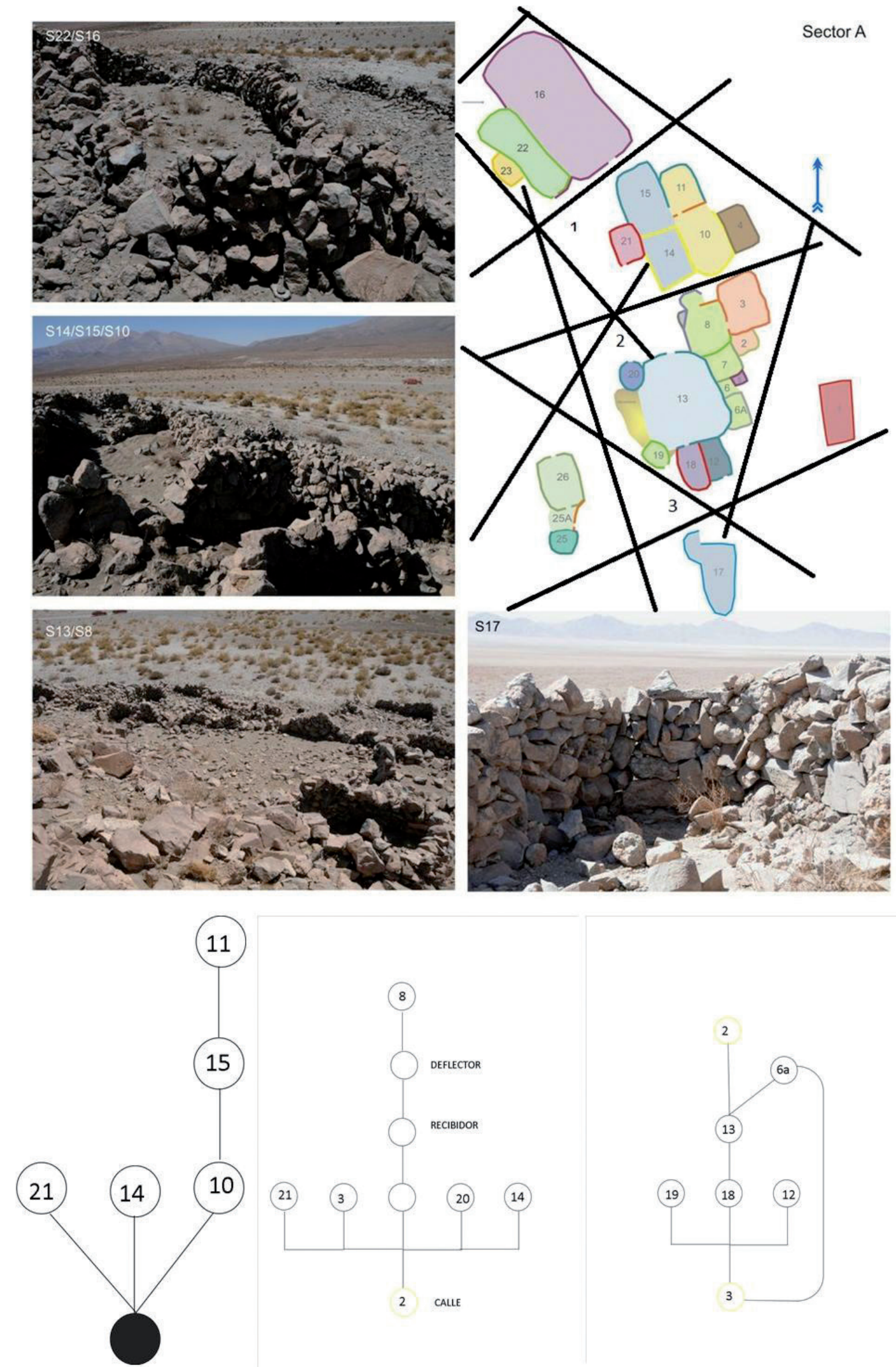

Figura 6. Gráficos de accesibilidad del sector A del pukara de Topaín. 
Finalmente en el extremo meridional de esta área baja vemos repetido el que denominamos 'módulo de vivienda tipo de Topaín', en este caso representado en la vivienda $10 \mathrm{~S} 017$, con granero, atrio, deflector y remate absidiado con ventana. Aún a pesar de tratarse de una unidad doméstica aislada, ésta mantiene la misma orientación en planta N-S que el resto del espacio construido. Este también es el caso de la casa emplazada en la cota más baja del sitio (ES10S001). Esta estructura aporta un dato sustancial a la hora de interpretar la evolución del asentamiento, ya que se construyó directamente sobre una terraza de cultivo como se comprueba en el paramento E. Por otro lado, la casa se emplaza directamente a la vera del canal que ciñe por el E el sector A. Entre la esquina SE de la vivienda y el canal se emplazaron intencionalmente una serie de bloques pétreos que canalizan el acceso hacia el asentamiento, y preceden a una suerte de pequeño muro perimetral que separa el espacio de la producción del espacio habitacional. Esta es su función real ya que el camino que marca acaba directamente sobre la ruptura de pendiente sin comunicar ninguna estructura habitada.

Por su parte, el sector B es el que concentra un mayor número y variedad de estructuras arquitectónicas (figs. 7 y 8). Dentro de esta zona el recorrido circulatorio por la abrupta ladera segmenta claramente un grupo de construcciones que denominamos área B1. Nuevamente nos encontramos aquí con una estructura que por sus características formales podemos definir como corral en la línea de la estructura 10S016. Le siguen una serie de unidades domésticas que reproducen el modelo-tipo ya conocido. De entre todas ellas destaca un complejo habitacional conformado por varias estructuras adosadas. Todas ellas se asientan sobre el mismo espacio aterrazado, entre el camino principal y el precipicio, y comparten muros siguiendo la línea de la pendiente. Aquí, el análisis de acceso y visibilidad nos permite identificar tres unidades con entrada directa desde el exterior. Se constata la existencia de una estrategia consciente de control del acceso (recibidores y deflectores). Así mismo, dos de las estructuras poseen sus propias estructuras de almacenamiento. En este sentido, por un lado, se deduce un cierto ideal de autarquía e independencia de estas tres viviendas, que se acrecienta si atendemos al hecho de que esas dos unidades poseen sus propias estructuras de carácter cultual. Pero por otro lado, observamos una clara conexión espacial entre las unidades, como se puede apreciar en la individualización del conjunto y la práctica del adosado. En este sentido, vemos aquí por primera vez un detalle arquitectónico que se va a repetir en el sector $\mathrm{B} 2$ : dos de las viviendas anejas que comparten muro enfrentan sus estructuras de carácter cultual en el mismo tramo. Esta relación microespacial puede corroborar la existencia de un vínculo estrecho entre los habitantes de las distintas viviendas. Volveremos sobre este tema más adelante.

E1 área B2 aparece perfectamente delimitada por el camino que asciende desde el pie del asentamiento. Se ubica en una zona alta en el que se ha llevado a cabo un notable trabajo de aterrazamiento. El mapa axial muestra la diferenciación clara entre las viviendas ubicadas en la ladera y esta arquitectura doméstica de carácter mucho más monumental (fig. 7). La aplicación del análisis de accesos nos permite identificar una unidad doméstica con un elevado grado de impermeabilidad espacial, ya que existe una estrategia intencional de control de la circulación por el interior de la vivienda. Para llegar a la habitación de mayor privacidad (10S064) el visitante o habitante debe cruzar obligatoriamente el umbral de ocho espacios sin tener contacto alguno con el exterior. Volvemos a encontrar aquí el ya conocido sistema de deflectores y recibidores. Esta casa compleja cuenta a su vez con una estancia a mayores que posee un acceso directo desde la calle, una puerta monumental ceñida por dos graneros que parece proyectar hacia el vial la riqueza y prestigio de la unidad doméstica. Este acceso permite entrar en una estancia en la que se ubica una estructura circular semisubterránea con una ventana que conecta con la estancia (10S064), esto es, la habitación más privada de la vivienda. A su vez, esta estructura cultual comparte pared medianera con otra de las mismas características (10S073) pero ubicada en la esquina $\mathrm{N}$ de la habitación contigua 10S070.

La parte NE de esta área B2 está ocupada por unidades domésticas vecinas que vuelven a repetir el modelo de casa-tipo con acceso directo desde un espacio público abierto y con granero y estructuras adosadas tipo chullpa. El espacio convexo que actúa como canalizador de la circulación da acceso a un espacio rectangular en el que se dispone una alineación de estructuras de almacenaje y cultuales semisubterráneas, con vanos y cubierta elaborada con sedimento amarillento de naturaleza arenosa. A diferencia de la casa compleja, que cuenta con estructuras cultuales en su interior, de uso privado, documentamos aquí un espacio de acceso directo desde el exterior y que parece remitir a un uso colectivo por parte de las viviendas más modestas emplazadas en esta zona del asentamiento de Topaín. 


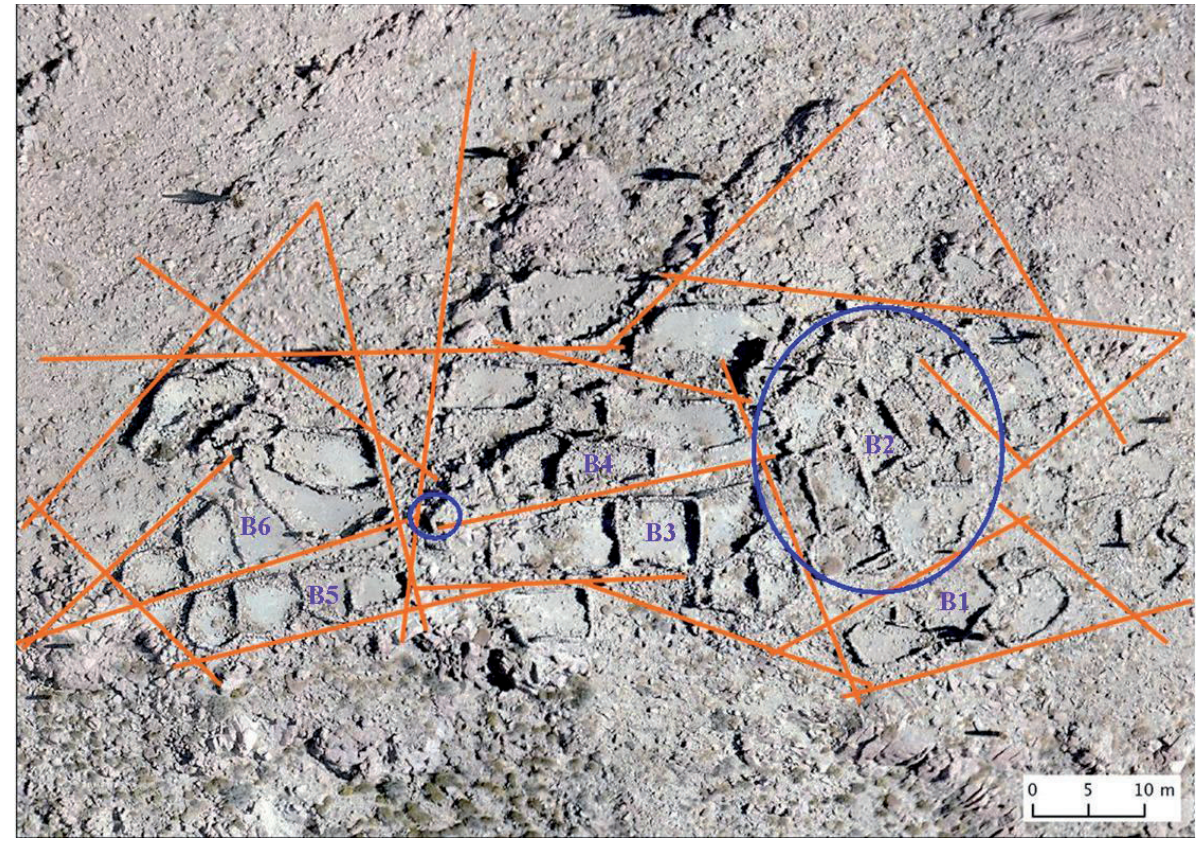

Figura 7. Mapa de axialidad del sector central (B) del pukara de Topaín. El cículo pequeño se corresponde con las dos chullpas centrales y el círculo grande indica la localización de la casa compleja.
Al otro lado de la calle se dispone el área B3, también individualizada por el camino y la calle principal. A nivel sintáctico comprobamos una característica que se repite por sistema en el poblado. A pesar de disponer de viales rectos que canalizan la circulación, las construcciones ubicadas a ambos lados jamás comparten espacio, es decir, nunca enfrentan sus entradas unas a otras. Esta constante evidencia una clara voluntad de individualización de las unidades domésticas. En este barrio distinguimos dos conjuntos diferentes de estructuras. El primero de ellos es un nuevo ejemplo de casa compleja, formada por varias estancias, con estructuras cultuales asociadas y un marcado control de accesos con deflectores y recibidores. Desde la calle se accede a dos habitaciones no conectadas entre sí pero que comparten en la pared medianera un complejo cultual formado por una mesa de ofrendas (en la estancia $\mathrm{S}$ ) y una chullpa (en la estancia $\mathrm{N}$ ). Nuevamente, una estructura ritual relaciona espacialmente construcciones habitadas por personas con un vínculo probablemente de parentesco, si vemos aquí evidencias de un culto a los ancestros y a los cerros tutelares (vid infra.). A su vez, la gran estructura rectangular $10 \mathrm{~S} 078$ se relaciona espacialmente con la vecina 10 S084 por un vano en la pared. El análisis sintáctico parece dejar fuera de toda duda el carácter habitacional de esta estancia (que da acceso a 10S083 y10S082). Con todo cabe destacar que esta estructura comparte ubicación, orientación, forma y presencia de vanos con las construcciones vecinas que se extienden hacia el $\mathrm{W}$ y que parecen tener una función más propia de espacios de agregación social a través del procesado colectivo de productos agrarios ${ }^{8}$.

A1 S de esta área B2 se presenta de manera aislada otra unidad doméstica que resume perfectamente el modelo tipo de vivienda que hemos definido para Topaín: módulo rectangular, interior indiviso, presencia de reflector, estructuras de almacenamiento y/o cultuales asociadas y voluntad manifiesta de independencia espacial con respecto a estructuras vecinas. Como podemos apreciar, este modelo de vivienda no ocupa el área residencial más conspicua sino que es relegada a zonas periféricas de media ladera.

$\mathrm{E} 1$ sector B4, emplazado al $\mathrm{N}$ de la calle principal, está compuesto por tres tipos de estructuras:

- Grandes estructuras ubicadas de la periferia del área habitada con acceso directo a los terrenos irrigados, y que formalmente se corresponden con corrales (10S056, 10S056a, 10S055 y 10S059).

- Unidades domésticas convencionales, con acceso directo desde la calle como la estructura $10 \mathrm{~S} 085$.

- Espacio que integra estructuras de almacenamiento y de carácter cultual (10S100).

\footnotetext{
${ }^{8}$ Comentario personal de Diego Salazar.
} 
Esta última estancia presenta una singularidad notable en el conjunto del asentamiento. De forma prácticamente cuadrada en planta (un unicuum en el poblado), se emplaza justo al final del primer tramo de la calle principal, al lado de las dos chullpas que constituyen el centro espacial y simbólico del recinto de Topaín (fig. 7). Perfectamente individualizada, esta construcción cuenta con un acceso semejante al de las viviendas (dos jambas careadas) pero en su interior no se registra un área de actividad propia de un espacio habitacional. Por el contrario, alberga una serie de estructuras excavadas en el sustrato, semisubterráneas, con falsa cúpula y pequeñas ventanas. Este espacio guarda ciertas concomitancias con aquel que identificamos en el sector B2, si bien cabe destacar una serie de diferencias sustanciales. En este caso no se trata de un acceso abierto desde el exterior, sino que las estructuras se concentran dentro de una construcción específica con un acceso definido y restringido. Nos encontramos, por lo tanto, ante una edificación con una funcionalidad especializada, probablemente centrada en el almacenamiento de excedente agrario.

El sector B5 participa de lleno del ordenamiento ortogonal que preside el asentamiento de Topaín. Las dos chullpas centrales sancionan simbólicamente el punto donde confluyen las vías de circulación principales, una longitudinal E-W y otra transversal N-S. Desde aquí parte otra calle en dirección $\mathrm{W}$ al sur de la cual se emplazan cuatro estructuras prácticamente idénticas. De planta rectangular y aparejo de mampostería de baja calidad, reaprovechan grandes bloques pétreos, carecen de deflectores $u$ otros elementos arquitectónicos que regulen el control del acceso y la visibilidad y presentan escasos materiales en superficie. De hecho en su interior no documentamos materiales diagnósticos como los que aparecen en las unidades domésticas que hemos definido como casas-tipo.

El sector B6 se ubica al $\mathrm{N}$ de la misma calle y en él se registran unidades habitacionales (una de ellas con dos estancias, 10S111 y 10S109) con acceso desde la calle. Completan el panorama grandes estructuras tipo corrales con puertas que abren hacia el camino que asciende desde la cara $\mathrm{N}$ para llegar a las dos chulpas centrales. Al NW un conjunto aislado de estructuras se ha visto afectado por una explotación primaria de cobre abierta tras el abandono de la ocupación del asentamiento. Finalmente en la vaguada que separa los dos primeros altozanos de Topaín se extiende el singular sector C del que nos ocuparemos más adelante.

\section{MONUMENTALIZACIÓN DE LA VIVIENDA Y DIVISIÓN SOCIAL}

\author{
Cuando golpeo me turban \\ igual que la vez primera. \\ El seco dintel da luces \\ como la espada despierta \\ y los batientes se avivan \\ en escapadas gacelas. \\ Entro como quien levanta \\ paño de cara encubierta, \\ sin saber lo que me tiene \\ mi casa de angosta almendra \\ y pregunto si me aguarda \\ mi salvación o mi pérdida. \\ Gabriela Mistral, Puertas.
}

El análisis arqueotectónico desarrollado en Topaín nos acerca a la lógica social que pudo presidir el espacio doméstico del asentamiento. En este sentido hemos podido analizar toda una serie de características formales, secuencias estratigráficas y relaciones espaciales entre las construcciones. Así pues, en el aparente caos urbanístico de Topaín documentamos, por un lado, un patrón de regularidad que facilita la identificación de espacios habitacionales (cultura material en superficie, artefactos domésticos, estructuras de combustión) y, por otro lado, una gran variabilidad formal que nos indica diferentes estrategias de construcción del espacio de la casa. De este modo, el trabajo desarrollado nos ha permitido definir cuatro tipos de edificaciones supuestamente habitacionales:

1. Recinto simple de planta cuadrada/rectangular, de aparejo de mala calidad y espacio único multifuncional. Estas construcciones se concentran en el extremo $\mathrm{W}$ del sector $\mathrm{B}$.

2. Vivienda-tipo: conformada por un módulo rectangular, acceso bien marcado, con recibidor y deflector. Presenta normalmente una estructura cultual y al menos una estructura de almacenamiento. Prolifera sobre todo en el sector A y en la ladera $\mathrm{S}$ del sector $\mathrm{B}$.

3. Vivienda-tipo pero conformada por dos o más estancias, con recorrido circulatorio entre ellas o accesos separados, pero siempre adosadas, integrando un conjunto doméstico separado del resto. Buenos ejemplos serían la casa 1 del sector A $(10 \mathrm{~S} 015,10 \mathrm{~S} 011,10 \mathrm{~S} 010)$ y la casa 2 del sector B (10S047, 10S036 y 10S035). 

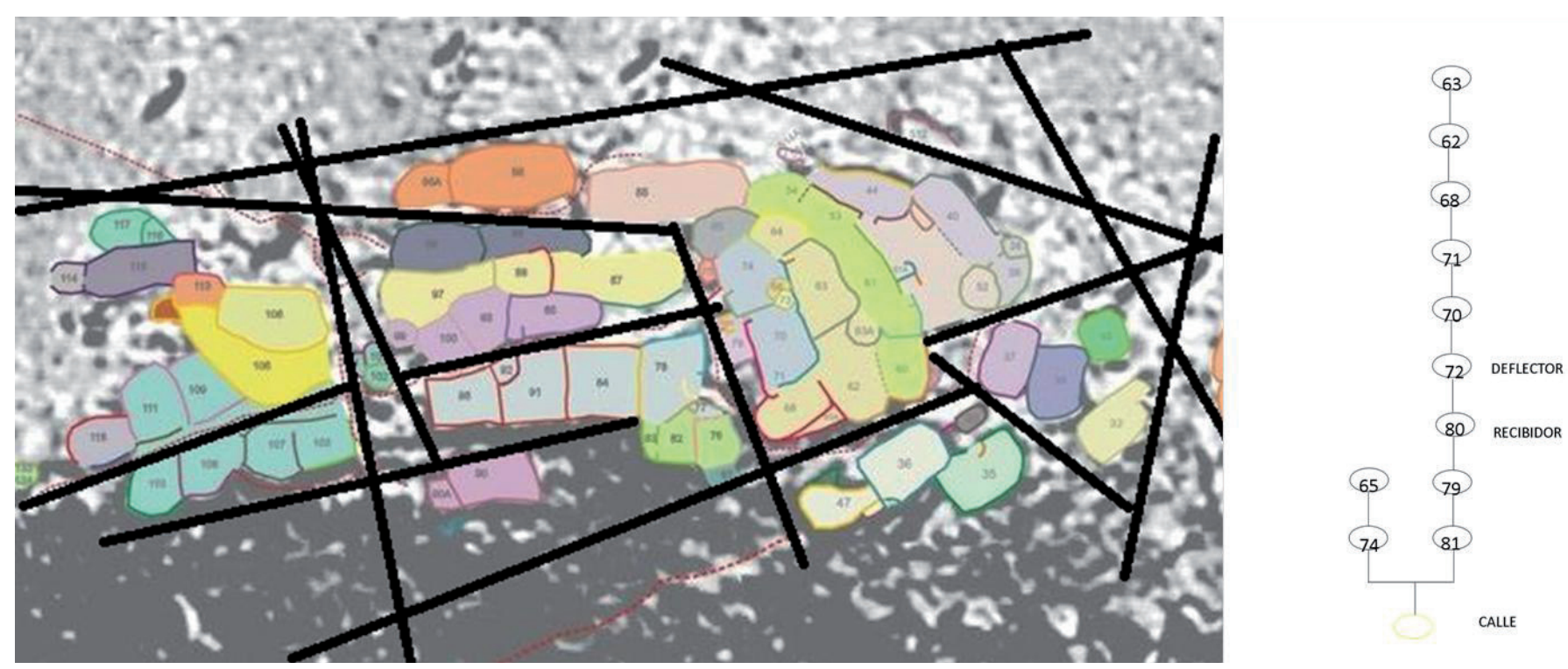

Figura 8. Principales ejes axiales del sector B y gráfico de accesibilidad de la casa compleja identificada.

4. Casa compleja. En esta categoría englobamos aquellas unidades domésticas que responden a las siguientes características formales (fig. 8):

- Ubicación en una zona preeminente del asentamiento. De hecho, el acceso principal se emplaza en los viales que ordenan el espacio y canalizan la circulación por esta área central del poblado.

- Monumentalización de la vivienda en aquellos puntos de contacto con el espacio público. Se constata una notable inversión de recursos en los accesos, paramentos exteriores y esquinales, en los cuales se emplea aparejo ciclópeo.

- Compartimentación interna con numerosas estancias y áreas de actividad especializadas.

- Presencia de estructuras de almacenamiento, presumiblemente destinadas para albergar la producción agraria de la unidad doméstica.

- Integración dentro del recinto habitacional de estructuras cultuales de uso privado.

Este modelo hipotético concreto conlleva la definición de estos tipos desde un punto de vista formal y espacial, esto es, no es nuestra intención abordar una aproximación tipologizante en el sentido de buscar únicamente indicios cronológicos. En la gramática del espacio doméstico de Topaín, estas unidades domésticas ${ }^{9}$

\footnotetext{
${ }^{9}$ Aplicamos el concepto de unidad doméstica tal como es planteado en el marco de la Household Archaeology: unidad de corresidencia basada en estructuras de parentesco y orientada a la producción, reproducción, distri-
}

se concretan en función de su morfología arquitectónica y sintaxis espacial. A este respecto nuestro análisis sirve para fundamentar dos hipótesis no planteadas hasta el momento: la casa como símbolo étnico e identitario y la existencia de un espacio doméstico jerarquizado en función de un determinado status socioeconómico.

\section{La casa como herramienta de construcción de la etnicidad}

El contexto postmoderno de la globalización, los cambios políticos producidos en los últimos años, la configuración de unidades políticas supranacionales en detrimento de las fronteras tradicionalmente entendidas, el resurgimiento de los nacionalismos, el mestizaje y la inmigración al primer mundo son quizás variables que explican el papel preponderante jugado por la identidad y la etnicidad en el debate de la teoría social en la última década (Pimentel 2003: 75-76). La reflexión teórica a este respecto ha acabado impregnando la disciplina arqueológica, sobre todo en el ámbito anglosajón, en donde tradicionalmente se han estudiado las comunidades del pasado desde una óptica funcionalista, como un conjunto de unidades familiares corresidenciales sometidas a la interacción del día a día y al peso de una cultura común. El todo social era la base de la reproducción social y biológica, de acuerdo con una visión internalista, estática, ahistórica y sistémica. El post-

bución y trasmisión de bienes, derechos y roles (Wilk y Rathje 1982; Allison 1999; Mayer 2002; Rivolta 2011) 
procesualismo reivindicó nuevamente el análisis de los condicionantes externos e internos de carácter histórico que determinan la estructura interna de toda comunidad. Así pues, en el marco de los últimos desarrollos teóricos de Arqueología contextual se han desarrollado diferentes aproximaciones como la denominada Archaeology of Communities (Yaeger y Canuto 2000a) que intenta dar buena cuenta de los procesos de construcción social de la etnicidad en las comunidades premodernas. Todas estas líneas de trabajo reivindican el análisis de la percepción y cosmovisión de la gente dentro de la comunidad y remarcan la experiencia social del espacio. Desde un punto de vista fenomenológico, la gente a través de los usos, las experiencias, los movimientos y las interacciones también influyen en los significados que vertebran las relaciones espacio-identidad-género. Una comunidad como Topaín es una institución dinámica socialmente constituida, no es únicamente una unidad socioespacial, un agregado de unidades domésticas, ya que estructura las prácticas de sus miembros dentro de espacios definidos y de un contexto histórico concreto.

La influencia de los planteamientos semióticos (Barthes 1986; Eco 1986, 1987) ha permitido a la investigación arqueológica considerar una cara de la Arquitectura hasta el momento inédita como es su carácter de signo de comunicación (Preucel 2006: 8- 14). El espacio construido no sólo presenta una funcionalidad pragmática sino que también es un objeto simbólico, ya que trasmite un mensaje que es asimilado de manera inconsciente dentro del marco espacial de la vida cotidiana. Esta perspectiva se ha aplicado al estudio de la arquitectura doméstica y monumental prehistórica poniendo de manifiesto la existencia de auténticos programas arquitectónicos e iconográficos en esas sociedades. La forma arquitectónica en definitiva es un significante que transmite significados culturales. De hecho, apenas se han abordado estudios de la cultura material del PIT desde ópticas que intenten analizar su papel como recursos icónico- visuales para transmitir información en la vida cotidiana. No debemos olvidar que estas comunidades premodernas carecían de escritura, conformando la cultura material un vehículo para la transmisión y materialización de los códigos culturales manejados por estas sociedades campesinas. La decoración externa de las viviendas, la manera de techar y de rematar las cubiertas de las chozas, la forma de decorar los cacharros o la decoración de ropajes y pieles adquirirían una dimensión textual como transmisores de significados no verbales.
Dentro de esta aproximación interaccional, la identidad no es inmutable, sino que se modifica, se construye y se cambia situacionalmente. Teniendo en cuenta esta realidad, resulta complicado aplicar al espacio doméstico del pasado clasificaciones taxonómicas inherentes a nuestro imaginario moderno occidental. Las viviendas y poblados no son meros escenarios fijos y asépticos en los que se desarrollan las acciones e interacciones sociales, sino que devienen referentes identitarios y étnicos de primer orden para comunidades que conviven con lugares, espacios y significados. A través del uso del espacio doméstico, de la construcción de la arquitectura doméstica, la gente define áreas de actividad, construye y recrea identidades (De Certeau 1984). Retomando a Bourdieu, la casa, como todas las formas espaciales, es todo un recurso mnemotécnico para sus ocupantes, es un generador de prácticas que construyen significado social, es un escenario en el que conviven diferentes percepciones, distintas identidades que también entran en conflicto (Moore 1986). La interacción social es clave para comprender el rol activo del espacio doméstico, de la cultura material en la construcción de la identidad individual y grupal.

Esta realidad se muestra claramente en zonas de frontera en donde se dan interacciones culturales entre distintos grupos étnicos. Este parece ser el caso de esta zona de la puna atacameña en el PIT. Un espacio en el que confluyen tradiciones locales (desierto), en el que se constata la presión de comunidades del altiplano y tienen lugar fenómenos de hibridación como el protagonizado por el denominado grupo cultural de Toconce. En este contexto (violento o no) multiétnico es central el papel de la arquitectura doméstica como herramienta de resistencia cultural y generador de identidad. A su vez, juega un rol fundamental el proceso de renegociación de la identidad y la resolución de conflictos. Dentro de este marco, creemos que la definición de lo que llamamos vivienda-tipo (fig. 9) se corresponde con una tradición constructiva propia de una comunidad concreta. La presencia sistemática de esta casa rectangular con deflector en el acceso remite a un esquema que puede relacionarse con la adscripción étnica de sus habitantes. En este punto, recordaremos que la arquitectura doméstica de una comunidad del presente y/o del pasado reproduce una determinada lógica social, un patrón cultural y una distintiva forma de estar en el mundo. Pero no sólo eso. Desempeña también un rol en la construcción material de la realidad social, condiciona, limita y canaliza la agencia social, el habitus, la praxis... o como queramos denominarlo en función el marco sociológico del que 

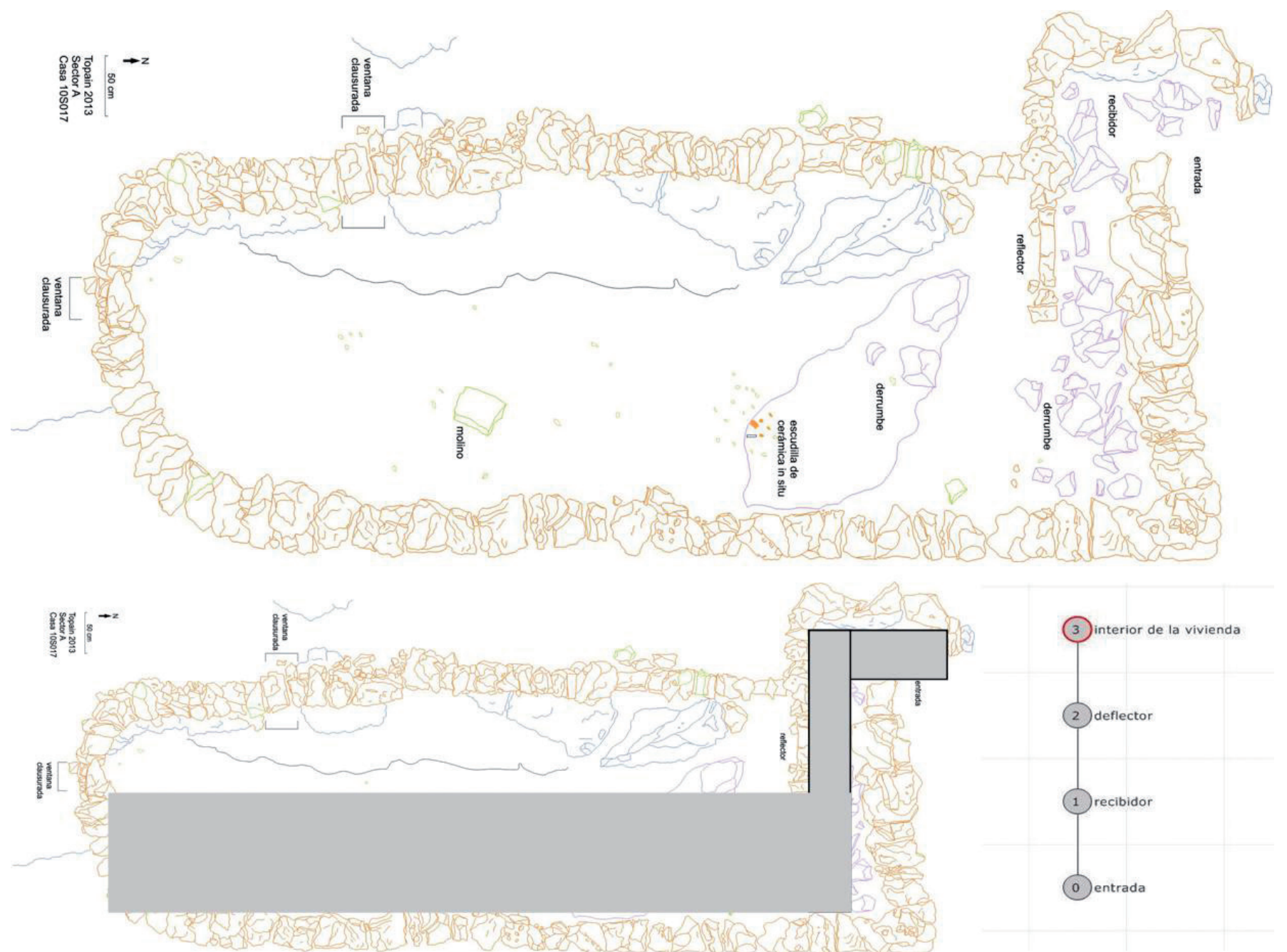

Figura 9. Arriba: vivienda tipo no 2 documentada en Topaín: planta de la estructura 10S017. Sector A. Abajo. Análisis de accesos. La trama gris se corresponde con el espacio semipúblico de la vivienda. El recibidor y el deflector restringen la visibilidad del interior por parte del visitante.

partamos. Nuestro trabajo etnoarqueológico con grupos étnicos de la frontera entre Etiopía y Sudán nos demuestra el papel de la vivienda como signo de comunicación no verbal y proyector de la identidad étnica de las comunidades premodernas (González, Ayán, y Falquina 2009; Ayán 2012b). En estas sociedades ágrafas, la etnicidad y la identidad se construyen a través de la materialidad (Fernández Götz 2008). La constatación etnoarqueológica $^{10}$ de este hecho cultural tiene unas consecuencias determinantes para intentar aprehender el trasfondo cultural de la vivienda con deflector de Topaín.

\footnotetext{
${ }^{10}$ En el marco de nuestro proyecto la antropóloga Viviana Manríquez está llevando a cabo un amplio trabajo de campo etnoarqueológico entre las comunidades locales. En su estudio está documentando prácticas tradicionales que pueden tener su correlato en la materialidad que estamos analizando: organización de viviendas y graneros, clausura simbólica de vanos, parentesco e identidad como ejes reguladores del espacio doméstico... (Manríquez 2015).
}

Este modelo arquitectónico obedece a una estrategia intencional tanto de la comunidad como de las unidades familiares, mediante las cuales se apropian y semantizan los espacios habitados, preservando memorias, activando conocimientos y construyendo identidad. Desde estas coordenadas, la casa con deflector no sólo restringe el acceso y la visibilidad, no sólo es un elemento de prestigio y una inversión, sino que puede ser concebida como un auténtico monumento mnemotécnico que reactualiza el sentimiento de pertenencia y denota etnicidad (fig. 9). La casa con deflector, unida a la presencia del fenómeno chullpario en Topaín, puede ponerse en relación con la presencia física en el asentamiento de gentes procedentes del altiplano. De hecho, en la zona boliviana de Lipez podemos identificar un modelo arquitectónico semejante. 


\section{Monumentalización de la vivienda y división social}

La casa es una estructura estructurante (Bourdieu 2002: 90), todo un sistema simbólico que refuerza las jerarquías sociales de las personas, los animales, los espacios y los objetos. Este sistema simbólico se establece, mantiene y reproduce a través de la práctica (cotidiana, social y ritualizada) en la que interactúan estrategias de poder y relaciones sociales (Hodder 1982: 132). El uso del espacio doméstico es especialmente importante dentro del sistema estructurante de la sociedad, ya que sanciona divisiones, impone jerarquías entre personas y refuerza los principios subyacentes de una cultura. El uso cotidiano del espacio doméstico deviene un modus operandi, una práctica social producto de la aplicación sistemática de principios coherentes que conforman un determinado patrón de racionalidad. De acuerdo con esta perspectiva la casa es un opus operandum a través del que se vehicula la organización social del espacio (Bourdieu 2002: 87-89).

A este respecto, el análisis sintáctico abordado en Topaín parece mostrarnos procesos determinantes en esta organización del espacio doméstico. Así pues, en primer lugar, detectamos una voluntad clara, en todos los casos, de individualización de la unidad familiar dentro del poblado, algo que quizás tiene que ver con la vigencia de un ideal de autarquía propio de una sociedad campesina. Se aprecia una estrategia de impermeabilización del espacio habitacional, la cual también hace uso de otras herramientas arquitectónicas que intervienen activamente en el funcionamiento del recorrido circulatorio interno, como es la presencia de atrios, machones salientes, pequeñas terrazas y deflectores en la puerta de entrada. Así mismo, el control del acceso parece remarcarse mediante la utilización de lajas de gran tamaño careadas para servir de jambas. Esta autonomía espacial de la vivienda-tipo se relaciona con un estilo arquitectónico propio que se deja entrever en todas las construcciones, independientemente de su tamaño o complejidad interna.

En segundo lugar, documentamos un tipo de casa compleja en la que se registran espacios distribuidores de la circulación, una notable compartimentación interna, un acentuado control del único recorrido posible dentro de las estructuras habitacionales. De este modo, se advierte la restricción establecida por la unidad social para preservar el espacio habitacional. Estas viviendas son un conjunto arquitectónico individualizado y cerrado, conformado por espacios que se pueden definir como espacio público, semipúblico/semiprivado y privado. Este proceso de segmentación se asocia, en los casos de las dos grandes casas del sector B, a una clara estrategia de monumentalización de la casa. A este respecto, compartimos uno de los presupuestos básicos de la Arqueología del Paisaje, aquel que afirma que todo lo visible es simbólico (Criado 1993: 42). Esta voluntad de visibilidad puede ser tanto consciente y explícita como implícita e incluso inconsciente: es la racionalidad de un grupo social la que determina qué rasgos de ese grupo serán visibles. De todas las estrategias de visibilización posibles se han definido cuatro básicas (Criado 1993: 45-51):

- Estrategias de carácter inhibidor: se definen por la falta absoluta de interés en destacar/ocultar la presencia de la acción social como productos, sin producir resultados o efectos intencionales, aunque cabe la posibilidad de que estos estén incorporados al registro arqueológico.

- Estrategias de ocultación: hay una intención consciente de invisibilizar la presencia de la acción social, lo que implica un rechazo de su existencia.

- Estrategias de exhibición: voluntad de que los efectos de la acción social sean visibles en el espacio.

- Estrategias de monumentalización: son las que pretenden, además de exhibir un elemento en el espacio, que éste perdure en el tiempo. Produce resultados intencionales de proyección temporal y espacial.

Cada uno de estos tipos de estrategias de visualización puede relacionarse con una determinada racionalidad cultural, o incluso puede emplearse como escala valorativa de las relaciones visuales de los elementos que conforman un espacio construido (fig. 10); precisamente identificar esta voluntad puede permitir valorar/ interpretar qué tipo de condiciones de visibilización/ estrategias de visibilidad están presentes en cada nivel espacial de un fenómeno, y en cierta manera, acceder a la parte del imaginario de una sociedad.

En el caso de estas dos casas de Topaín vemos materializada una clara estrategia de monumentalización en el seno del poblado. En los dos ejemplos se maximizan las condiciones de visibilización del solar, se levantan potentes terrazas, se realzan los paramentos murarios con el empleo de aparejo ciclópeo y se utiliza una cuidada mampostería. Estas casas complejas son dueñas 


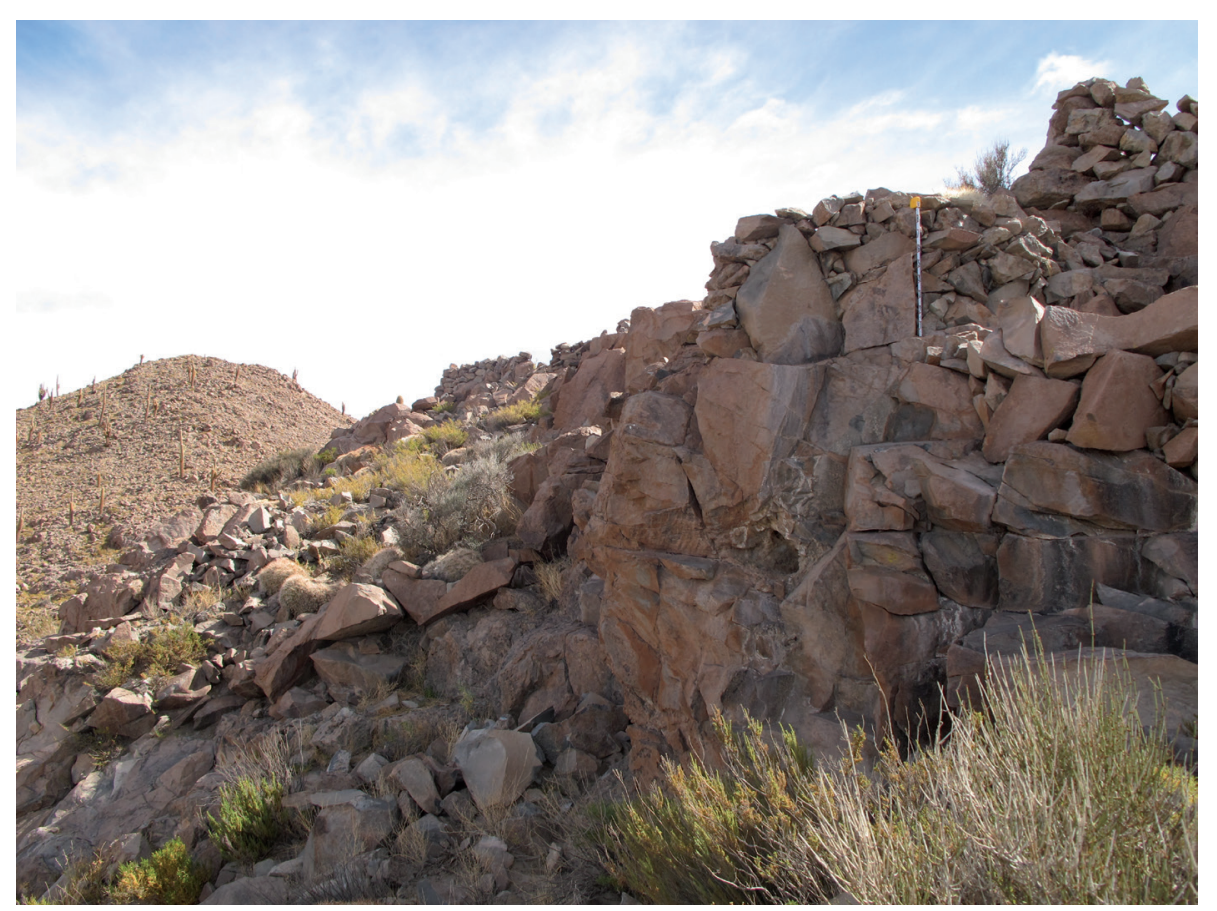

Figura 10. Arquitectura orgánica y estrategia de invisibilización de un poblado en altura: vivienda del sector $B$ integrada en el cerro de Topaín. absolutas de la gestión del espacio conformado por la parcela, por el solar en el que se asientan. Cerradas sobre sí mismas, actúan como estructuras autónomas y autosuficientes, con una complejidad interna notable gracias a compartimentaciones internas y la presencia de construcciones con una función especializada. Dentro conviven los miembros de la familia, y los bienes que comportan riqueza y prestigio al agregado familiar. El control de los accesos, del recorrido circulatorio, la búsqueda de la privacidad de la unidad doméstica son estrategias espaciales que manifiestan un deseo de autoafirmación de la familia. La casa es todo un símbolo identitario de los miembros que residen en ella. La vivienda posee su propia metahistoria, tiene un pasado vinculado con los antepasados, es un escenario para la acción social que se reactualiza con el paso del tiempo.

Estas dos casas-monumento son auténticos símbolos de prestigio social, escenografías arquitectónicas que nos remiten a un asentamiento en el que se comienza a atisbar una cierta jerarquización social, a diferencia de lo que parece ocurrir en otras áreas limítrofes en las que sigue primando un ideal comunitario (Nielsen 2002; Acuto 2007). Determinadas unidades domésticas, con características más modestas, se ubican en la ladera (fig. 10) y la zona baja, mientras estos grupos se escinden del todo social, almacenando excedente e invirtiendo notables recursos en su arquitectura doméstica. La casa, como materialización de la unidad familiar, pasa a ser, como decíamos antes, el marcador de la identidad, de la jerarquización social, del prestigio y del poder. La monumentalización y ritualización del espacio doméstico, la sanción simbólica de la propiedad son todas evidencias materiales de un proceso de desigualdad social en el que comienzan a visibilizarse determinadas unidades domésticas vinculadas a linajes concretos.

En definitiva, podemos atisbar la emergencia de un proceso de división social, bastante claro si comparamos la gran casa del sector B con el resto de unidades habitacionales. La proliferación de estructuras de almacenaje, proyectadas hacia el exterior, hacia el espacio público, nos hace pensar en el control de excedente agrario en una cuantía superior a las viviendas medias. Por otro lado, la documentación de una estancia específica de almacenaje en el sector B nos plantea un interesante dilema: o ese almacén es de uso comunitario o está controlado por una unidad doméstica (o varias) que tiene el poder y la legitimación para concentrar y redistribuir esa producción agraria generada por el trabajo en las terrazas de cultivo.

\section{COSMOLOGÍA, DISEÑO URBANO Y RITUALIZACIÓN DEL ESPACIO DOMÉSTICO}

Porque es así que cada provincia, cada nación, cada pueblo, barrio, cada linaje y cada casa tenía dioses

diferentes unos de otros porque les parecía que el dios ajeno, ocupado con otro, no podía ayudarlos, sino el suyo 
propio. Y asi vinieron a tener tanta variedad de dioses y tantos que fueron sin número (Garcilaso de la Vega 2005 [1609], Vol. I, Lib.1, Cap. IX: 28). (recogido en Pimentel 2009: 11)

El análisis arqueotectónico planteado para el caso del sitio de Topaín abre la puerta a nuevos enfoques sobre el surgimiento y desarrollo de esta forma urbana. Hasta el momento se había considerado este yacimiento arqueológico como un espacio habitacional menor, secundario, satélite, en comparación con los grandes aglomerados o sitios multicomponentes (Castro y Cornejo 1990: 57) como Paniri o Turi. Quizás por ello siempre se ha minusvalorado la posible existencia de un ordenamiento urbanístico en Topaín (Urbina 2010: 126-127). Creemos que nuestro trabajo contribuye a matizar y poner en tela de juicio esta visión que minusvalora el carácter urbano del asentamiento de Topaín. Sin duda, la identificación del sistema de terrazas habitacionales demuestra, como en el caso también de las terrazas de cultivo, una planificación previa). A la hora de construir las edificaciones éstas se van levantando siguiendo un modelo aditivo mediante adosados, siguiendo el sentido de la pendiente. Este crecimiento del asentamiento no es desordenado sino que se desarrolla en función de unas vías de circulación claras. Cuando el poblado, en una fase posterior abandona el emplazamiento en altura, conquista la zona baja (sector A) pero adoptando el mismo patrón urbanístico con viales E-W y unidades domésticas con una orientación N-S. Aquí vemos como esta organización del espacio no está condicionada por la orografía sino que obedece a un diseño urbano concreto, a una decisión culturalmente condicionada.

Como en el caso del asentamiento de Likan (Aldunate, Berenguer y Castro 1982), el registro arquitectónico de Topaín reproduce un estricto patrón espacial, una topología ritualizada en la que la proximidad a la cumbre del cerro y la orientación hacia las montañas y volcanes juegan un papel esencial como ordenadores simbólicos del espacio habitado (fig. 11). Como decíamos antes, nuestra experiencia etnoarqueológica nos muestra cómo en las comunidades premodernas que carecen de escritura toda la información se transmite por medio de la cultura material, que deviene todo un signo de comunicación no verbal. A su vez, la arquitectura de los asentamientos y la propia casa son en sí mismos espacios ritualizados que reproducen la cosmología y la manera de estar en el mundo de sus habitantes (Rivolta 2011: 232-233). A este respecto es importante consignar aquí la importancia de la orientación ritual de vanos y puertas de las construcciones, y de las ventanas de las chullpas, hacia los cerros tutelares que protagoniza el paisaje de esta zona (fig.11). Esta cuestión se introdujo en el discurso arqueológico gracias a la original e interesante aproximación etnohistórica llevada a cabo por el equipo Toconce (Berenguer, Aldunate y Castro 1984). El trabajo de campo desarrollado en la década de 1980 en esta zona de la puna atacameña les hizo reconocer el papel central de montañas y volcanes como ejes vertebradores del paisaje simbólico.

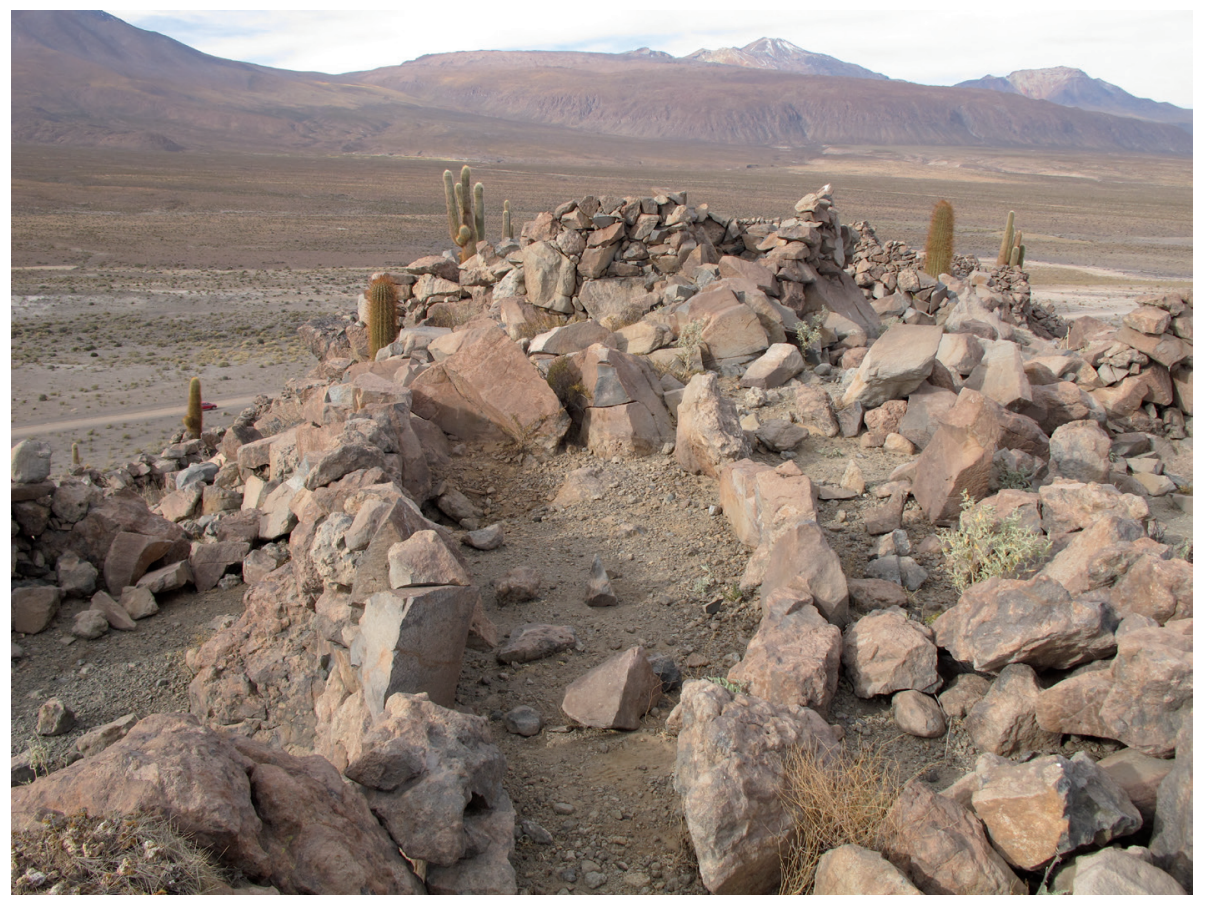

Figura 11. Deflector que canaliza el acceso a las dos chullpas centrales, verdadero espacio cultual vertebrador del espacio. Al fondo, los cerros tutelares de Aguas de León y Toconce. 


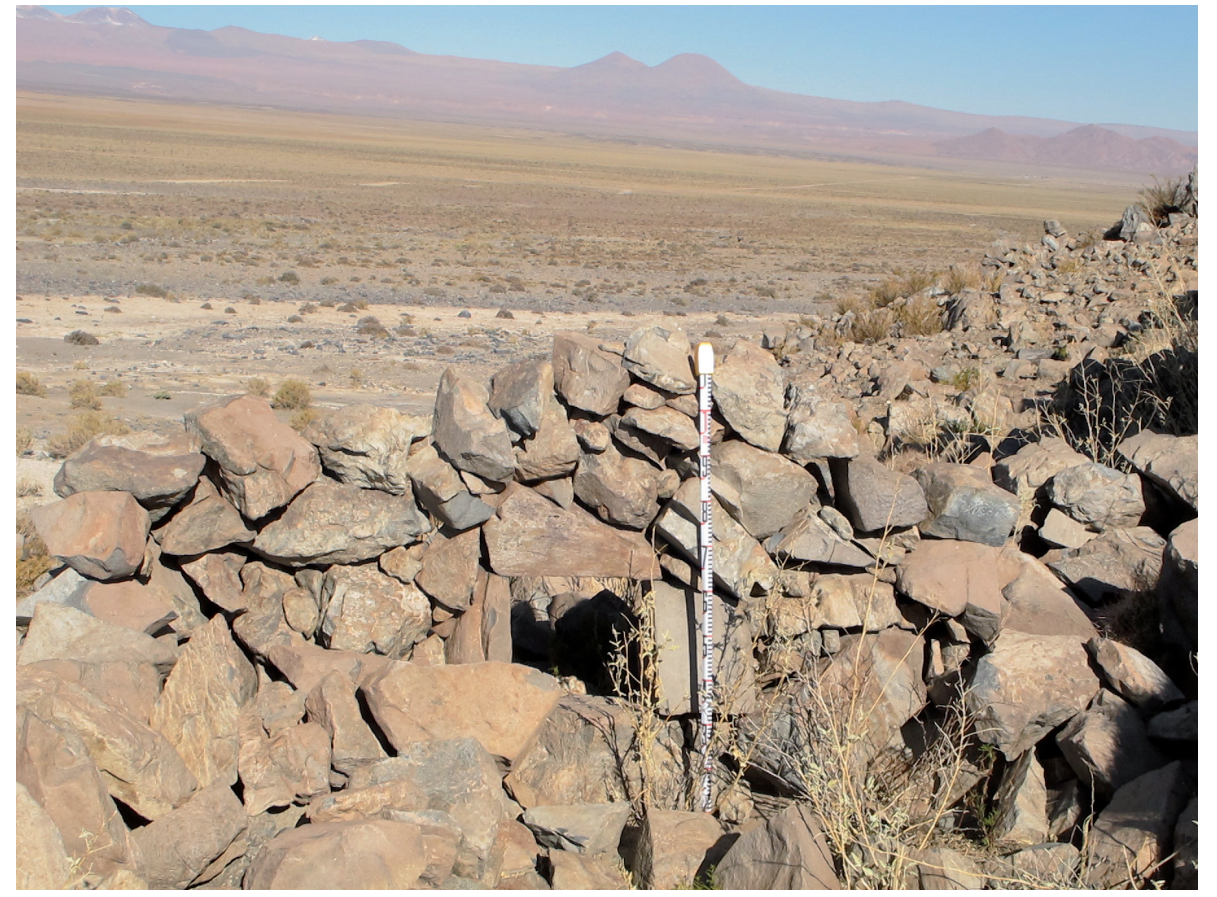

Figura 12. Orientación del vano de una estructura doméstica del sector $\mathrm{A}$ : al fondo, la montaña femenina Q'aulor y la montaña masculina Chita.
Así pues, las comunidades locales creen que las montañas son estrellas que descendieron a la tierra, mientras que los volcanes regulan el funcionamiento de la tierra, ya que son volcanes de fuego (Licancabur), agua (San Pedro) y viento. Éstos dos últimos son responsables de la lluvia y de la tormenta (Castro y Aldunate 2003: 73). Las montañas (denominadas Mallku en lengua aymara) son espacios sagrados con varios niveles de significado; son lugares míticos de origen, habitados por los ancestros, son también elementos propiciatorios de la fertilidad y la riqueza, son altares (mesas) y vivienda de las divinidades.

El asentamiento de Topaín ejemplifica perfectamente la hipótesis defendida por Castro y Aldunate en su trabajo con las chullpas de los asentamientos de Likan y Quebrada Seca. Según ellos, las ventanas de estas estructuras cultuales no se orientaban únicamente hacia los puntos cardinales, sino hacia las montañas sagradas y volcanes (Castro y Aldunate 2003: 76). En nuestra opinión, esta orientación ritual es una variable muy tenida en cuenta en la planificación topológica y urbanística del asentamiento ${ }^{11}$. Las calles presentan una disposición en planta E-W con el cerro Topaín y el Cerro León como referentes topográficos claros (fig. 11). El Cerro León está estrechamente vinculado en la actualidad a la comunidad

\footnotetext{
${ }^{11}$ En esta misma línea se sitúa el reciente trabajo de Cristian González: Análisis arquitectónico de las estructuras tipo chullpa de Turi, Topaín y Panire. Informe de práctica profesional presentado en la Universidad de Chile en 2014.
}

indígena de Toconce. Considerado como una montaña masculina recibe diferentes nombres: Mallku Kulliri, Cerro León, Mallku Agua de León y Puma Urko. Guardián de las riquezas de los ancestros, es especialmente dadivoso, protege el ganado y propicia la lluvia. Este papel clave en la reproducción y supervivencia de las comunidades hace que reciba pagos y ofrendas para ganarse su favor (Castro y Aldunate 2003: 77). Hacia este Cerro León se orienta la calle principal del sector B de Topaín, una de las dos chullpas centrales (fig. 11) y el alineamiento de vanos que recorren las estancias de la estructura compleja del sector B3. Hacia el S la totalidad de los vanos documentados se orientan en dirección a dos montañas estrechamente ligadas a la localidad de Caspana. Más pequeños, de forma redondeada y casi nunca cubiertos de nieve, son la montaña femenina Q'aulor (o Sipitare Mama, o Mama Sipaqa) y la montaña masculina Chita (Sipitare Tata) (fig. 12).

A nivel de espacio doméstico, la orientación de los vanos de las estructuras cultuales privadas nos sugiere otra interesante cuestión. Si planteamos la posibilidad de que Topaín sea un asentamiento multiétnico, un reasentamiento de poblaciones procedentes de otros lugares para habilitar todo el terrazgo y sistema de irrigación con el objeto de producir nuevas tierras de cultivo, resulta sugerente pensar que esa orientación recuerda el origen de la unidad familiar de la casa, estrecha el vínculo entre el cerro tutelar originario y la nueva vivienda. Como ha señalado Nielsen $(2006 a, 2009)$ a través del 
culto y centralidad de las chullpas en el paisaje de los poblados se construiría y legitimaría la filiación de los distintos linajes en torno a los antepasados, así como de la comunidad en relación con sus ancestros. Estos a su vez, legitimarían las reclamaciones y derechos territoriales de estas comunidades.

Sea como fuere, lo que demuestra el análisis formal es que en Topaín, además de contar con espacio ceremonial comunitario específico (sector C) (fig. 13), las propias unidades familiares desarrollan sus propios escenarios para la ritualidad. Este fenómeno de ritualización se constata a través de chullpas adosadas o incorporadas a la propia estructura modular de la casa (como en el ejemplo de la vivienda 10S017), de pequeñas mesas en las esquinas interiores o asociadas a una estructura cultual compartida entre estancias con accesos diferenciados. Esta privatización del espacio ideológico y religioso que se da en las unidades domésticas de Topaín es una consecuencia más del valor simbólico de la casa, que cuenta con sus relatos míticos, sus historias y leyendas, sus propios dioses y sus propios rituales, como parece colegirse de la cita de Garcilaso de la Vega que encabeza el presente apartado. La familia es una comunidad de vivos, pero también de muertos. El culto a los antepasados, la evocación de los muertos forman parte del capital simbólico acumulado por la unidad doméstica.

Aparte de esta sacralización de la casa, vemos cómo se impone una idea de comunidad sobre las unidades familiares. En este sentido, en Topaín nos encontramos con espacios arquitecturizados claramente ritualizados que ocupan una posición simbólica central dentro del asentamiento. Por ejemplo, las dos chullpas centrales parecen proteger a la comunidad entera. Este es un ejemplo bastante claro de espacio ritualizado integrado en el seno de la comunidad, difícilmente adscribibles a élites o grupos de poder escindidos de la colectividad.

\section{TOPAÍN COMO ESCENOGRAFÍA RITUAL}

El cerro-isla de Topaín, ubicado en la precordillera del río Loa, en una planicie aluvial, continúa siendo un referente simbólico en el paisaje cultural de este territorio. Todavía en la cumbre se pueden ver los restos materiales de ofrendas cerámicas, relacionadas con rituales performativos realizados por las comunidades locales. Estos objetos ritualizados se orientan hacia el volcán de Aguas de León, una de las montañas sagradas vinculadas a la cosmovisión compartida con matices tanto por los habitantes del PIT, como por la población Inka o por la actual comunidad indígena atacameña de Ayquina-Turi (Castro y Aldunate 2003).

En el siglo XXI el cerro de Topaín sigue siendo la residencia en la tierra de los abuelos y los comuneros, como nos recordó un vecino en la reunión de presentación del proyecto ante la comunidad, son los legítimos herederos de los abuelos.

En este contexto, la Arqueología supone, en cierta medida, una nueva agresión a la naturaleza cultual del cerro de Topaín. Es por ello que toda intervención arqueológica debe tener en cuenta el carácter multidimensional del sitio; éste no es un fósil arqueológico, sino un espacio vivo, repleto de significado. Dentro de estas coordenadas el cerro de Topaín sigue siendo objeto de pagos y cultos. Incluso en la ladera $\mathrm{N}$ del yacimiento podemos ver pequeños depósitos de malaquita en grietas de la roca orientadas hacia el Paniri. Esta relación entre cerro y culto es muy propia de estas comunidades atacameñas actuales. Incluso en la tradicional fiesta de la limpieza de canales se desarrollan ofrendas a los cerros tutelares empleando una piedra como trasunto material del Mallku' ${ }^{12}$.

Si Topaín, como otros elementos orográficos de la región, sigue siendo un espacio sacral en la actualidad no debemos obviar que probablemente también lo fue en el PIT. Ya apuntamos temas como la ritualización del espacio doméstico o la existencia de un orden espacial que remite a un modelo topológico concreto. Sin embargo, las evidencias empíricas de mayor calado para sustentar esta hipótesis vienen dadas por la escenografía ${ }^{13}$ arquitectónica generada por las dos chullpas centrales y por el llamado sector C (fig. 13).

En las dos chullpas (una de ellas orientada al cerro León y la otra al propio cerro Topaín) vemos materializada toda una estrategia de monumentalización. En ambas confluyen las dos grandes calles del sector B; su estructura se realza al ubicarse en un punto de amplia visibilidad, pero también al sobreelevarse sobre el propio sustrato rocoso. Se configura así un auténtico panóptico desde el que se observan todos los cerros tutelares. El acceso a las chullpas desde el W es canalizado a través de una línea de piedras que recuerda al deflector presente en muchas unidades domésticas de Topaín. A este respecto, creemos que podemos defender una cierta relación

\footnotetext{
12 Comentario personal de Manuel Prieto.

${ }_{13}$ Mientras la investigación arqueológica ha hecho hincapié en el trasfondo ideológico de las escenografías generadas por el Imperio inka y sus imitaciones locales (p. e. Moore 1996; Coben 2006; Leibowicz 2012), apenas se ha abordado esta dimensión de la arquitectura doméstica en contextos preincaicos.
} 
metafórica entre las chullpas y el espacio habitado. De hecho, estas dos estructuras se asientan en un espacio en el que se habilitan muros de contención innecesarios, con una funcionalidad más escénica que práctica. Da la impresión de que estamos ante una versión en miniatura de la arquitectura aterrazada que caracteriza al asentamiento.

Por su parte, la arquitectura del sector C se emplaza en la subida a lo alto del cerro, es la zona en la que desemboca el recorrido circulatorio desde los pies del asentamiento (fig. 13). Una característica esencial de este espacio es la presencia sistemática de depósitos de malaquita, que comienzan a aparecer ya en el límite $\mathrm{W}$ de la calle principal. Aquí registramos una primera estructura circular con acceso y suelo challado (ES130709J01). Estas ofrendas cupríferas (la comida de los dioses) forman parte de una práctica tradicional de las comunidades preincaicas e incaicas (Pimentel 2009: 29). Este conjunto del sector $\mathrm{C}$ nos recuerda, a pequeña escala, a los espacios ceremoniales documentados en el interior del gran asentamiento vecino de Turi: grandes espacios rectangulares abiertos que preceden a estructuras normalmente de planta oval con acceso restringido y orientado hacia estructuras cultuales (habitualmente chullpas en el caso de Turi; en González 2014). El análisis de accesos muestra una voluntad clara del control de la circulación por este espacio ceremonial. De entre todas las estructuras destaca por su carácter aislado y calidad en la construcción, la edificación 10S123. Cuenta con una puerta monumental y un vano claramente orientado al Paniri.

$\mathrm{Al} \mathrm{W}$ de este conjunto arquitectónico, sobre el punto más alto, se define en planta una estructural cultual de planta rectangular, subdividida en dos estancias, con una orientación clara hacia el cerro León. Parece vincularse al modelo formal de los muros y cajas propio de las regiones del Loa Medio y la subregión del río Salado y que algunos autores vinculan con vías de circulación prehispánicas (Sinclair 1994; Berenguer 2004; Pimentel 2009; Urbina 2010).

Esta variabilidad de formas arquitectónicas cultuales documentada en el asentamiento de Topaín pone de manifiesto los procesos de interacción cultural que tuvieron lugar en esta zona de frontera en el PIT. Por otro lado, nos permite volver sobre un tema ya abordado con anterioridad: la materialización de la etnicidad. En este sentido queda por dilucidar si Topaín es un poblado multiétnico o un asentamiento nuevo fundado por comunidades del altiplano que se apropian de nuevas tierras de cultivo en una zona de
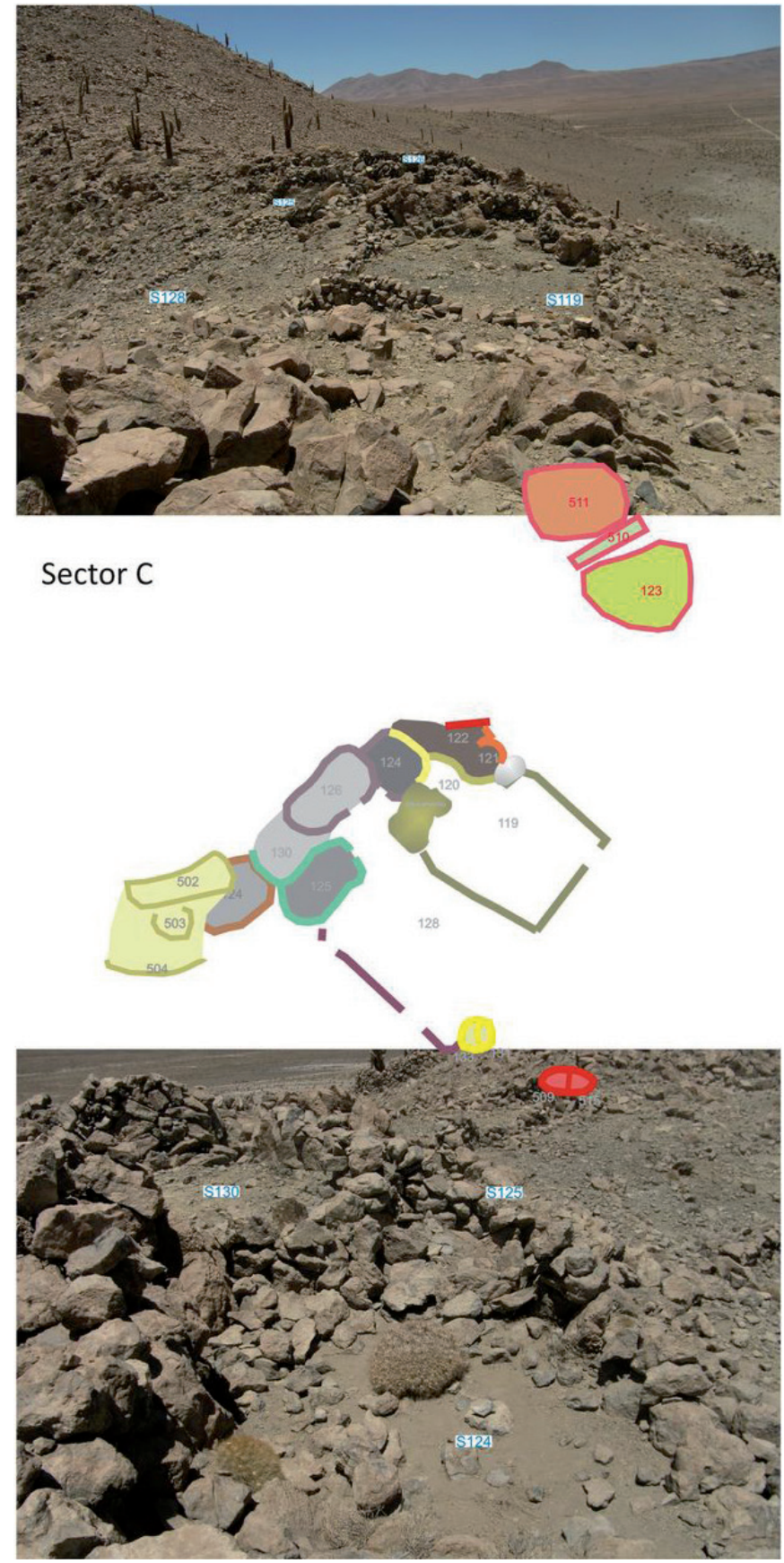

Figura 13. Sector C del pukara de Topaín, en el ascenso a la cumbre del cerro.

tránsito natural como es ésta. Sea como sea, la arquitectura performativa de Topaín se puede relacionar con un claro proceso de territorialización por parte de comunidades campesinas que construyen un paisaje cultural a partir de los cerros tutelares, los recursos hídricos y las terrazas de cultivo (fig. 14).

Finalmente, el carácter de escenografía ritual que parece vislumbrarse en Topaín se incentivó, paradójicamente, con su abandono como espacio habitacional. Así 
pues, hemos registrado ejemplos más que significativos de clausura intencional de vanos (tanto puertas como ventanas) en unidades habitacionales, espacios comunales y estructuras cultuales. Sirva de ejemplo paradigmático el caso de la casa con deflector 10S017 el sector A. Sus dos vanos fueron sellados, mientras que en el centro del suelo ocupacional se depositó una escudilla tipo Dupont con cenizas en un agujero marcado por una pequeña laja hincada. Sobre esta estructura se ubica el derrumbe interno de los paramentos murarios. Rituales de abandonos de espacios domésticos de este estilo se documentan en numerosas sociedades premodernas, variando desde el incendio ritual de la casa que se abandona hasta el sellado simbólico de puertas y ventanas.

\section{VALORACIÓN FINAL: REPENSANDO TOPAÍN}

No cabe duda de que una reflexión o una investigación sobre el origen de la desigualdad, en el sentido en que las sociedades primitivas son precisamente sociedades que obstaculizan la diferenciación jerárquica, puede suscitar una reflexión sobre lo que sucede en nuestras sociedades. (P. Clastres: La sociedad contra el Estado).

Los paisajes arqueológicos muestran la forma de estar en el mundo de las comunidades que lo habitaron y lo construyeron a lo largo de la historia, sus relaciones sociopolíticas, pero también, como un palimpsesto, son

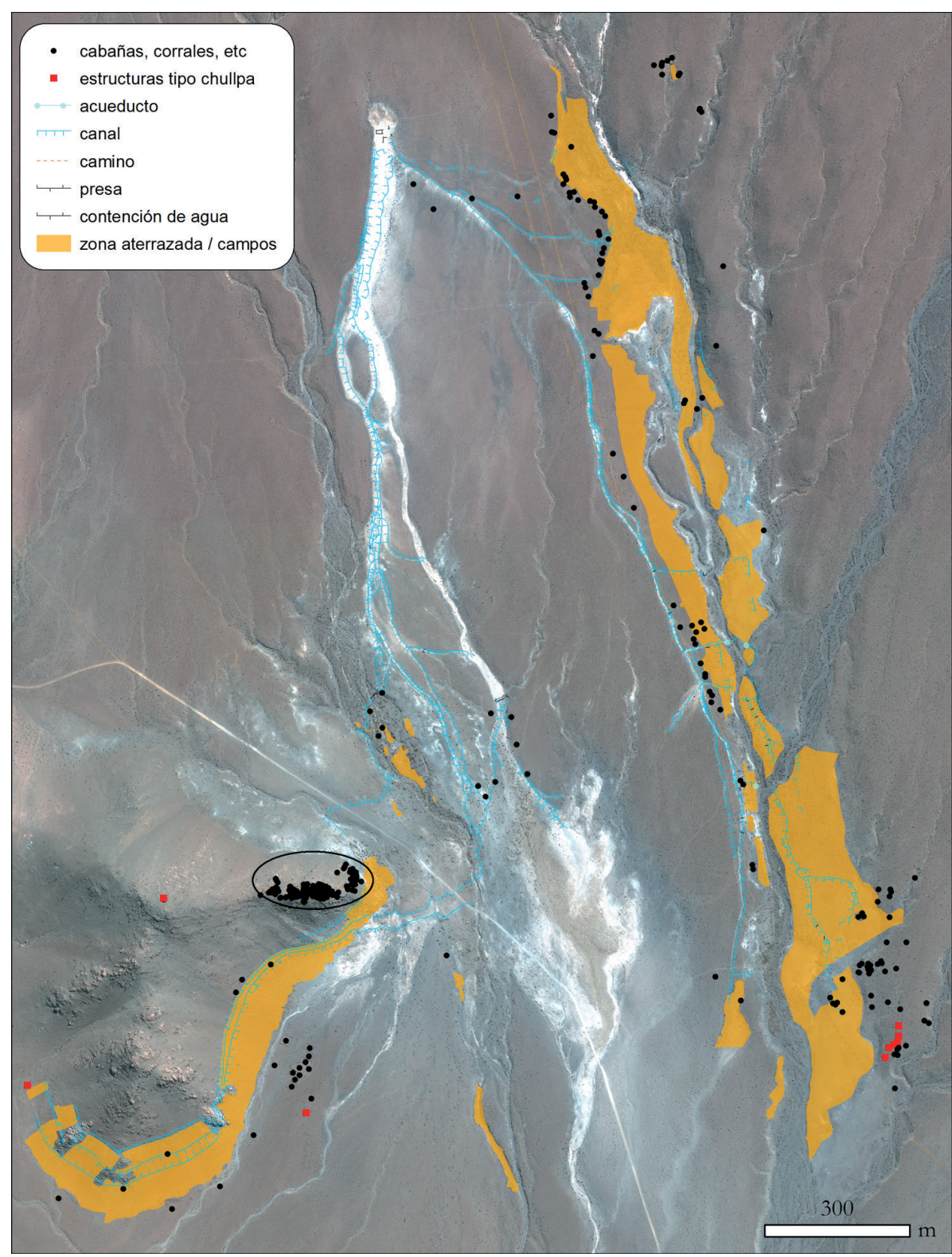

Figura 14. Sistema hidráulico y terrazas de cultivo documentadas en el entorno del asentamiento de Topaín (éste señalado con un círculo). 
el resultado final de procesos recurrentes y cíclicos en los que son continuamente alterados y reinterpretados (Thomas 2001: 173). Las relaciones sociales, la práctica diaria (habitus sensu Bourdieu 1997) la negociación constante, la experimentación del espacio y del tiempo, la gestión de la memoria y el olvido son procesos espacializados y materializados en esa construcción social, cultural y política, en esa performance de la vida social que es el paisaje (Bender 1993: 111).

El cerro de Topaín es el elemento vertebrador de todo un paisaje cultural orientado a la producción agraria en un difícil nicho ecológico. Para garantizar la supervivencia de la comunidad se desarrolló toda una impresionante arquitectura hidráulica (fig. 14), pero también se construyó un poblado en altura, fortificado mediante una arquitectura orgánica que une inextricablemente comunidad, emplazamiento, cerros tutelares y dioses. El yacimiento, por tanto, se vincula con el proceso de territorialización de una comunidad campesina, un proceso probablemente conflictivo y truncado con la llegada del Imperio Inka.

Los grupos humanos asentados en Topaín configuraron colectivamente toda una escenografía arquitectónica, levantaron un poblado monumental para ver y ser visto, sancionado simbólicamente con espacios comunitarios cultuales como el sector C. El trabajo comunitario que se deduce del ingente esfuerzo para edificar terrazas de cultivo y habitacionales hace prevalecer el todo social por encima de las unidades familiares del asentamiento. Este valor colectivo se acompaña de un modelo arquitectónico doméstico compartido por la comunidad, sancionado por una determinada tradición cultural. El modelo de casa-tipo identificado en nuestro trabajo puede actuar como indicador material de la etnicidad de la comunidad aquí asentada. La vivienda con deflector y el fenómeno chullpario son argumentos que redundan en un posible origen altiplánico de esta población.

Siempre se ha concebido Topaín como un asentamiento agropastoril secundario, satélite, formado por gente dependiente, mera ejecutora de procesos productivos controlados por otros. Nunca se plantea la posible existencia de comunidades autogestionadas, al margen de poderes alóctonos, de centros y lugares centrales. Igual que la extinta vega de Topaín era un archipiélago en un mar de puna y arena, también esta comunidad podía ser un archipiélago en medio de sociedad estatales o encaminadas hacia el Estado. A este respecto, nuestro análisis arqueotectónico pone de manifiesto un proceso no detectado hasta el momento. A pesar del peso de la tradición y de los valores comunitarios, se atisba en Topaín una emergente división social, síntomas materiales claros de una jerarquización interna. Esas casas complejas nos hablan de unidades domésticas con mayor capacidad de producción, almacenamiento y redistribución, de viviendas que acumulan también un notable capital simbólico dentro del poblado.

Esta realidad doméstica que hemos podido esbozar en las presentes páginas abre el camino para plantear la posibilidad de la aparición de élites locales en esta zona de la puna atacameña en la fase final del PIT. Estos grupos jugarían un papel sustancial en la configuración del nuevo modelo de ocupación del territorio por parte del Imperio Inka. Por ahora no existen evidencias de una conquista violenta de esta región, por lo que resulta factible una asimilación de estos jefes locales, clave en la renegociación de la identidad y en la instauración de un nuevo orden social. Este fenómeno de división social atisbado en Topaín alcanza su pleno desarrollo en el vecino asentamiento de Turi, en donde el espacio doméstico muestra claramente las diferencias de status socioeconómico entre unidades familiares.

Finalmente, nuestro trabajo ha intentado mostrar el papel fundamental jugado por Topaín como escenografía ritual. Parafraseando a Neruda, este lugar es una residencia en la tierra, no sólo de una comunidad, sino también de los dioses. Sin abordar el proceso de ritualización de este espacio doméstico seguiremos corriendo el riesgo de acercarnos a un registro arquitectónico complejo partiendo de ideas preconcebidas y de enfoques que buscan analizar Topaín desde otros sitios y desde otros horizontes. Como decíamos al principio, recuperar el sentido de lugar de Topaín, desde su propia materialidad, es el objetivo marcado por nuestro proyecto. Y para alcanzarlo, el análisis arqueotectónico y el análisis sintáctico son herramientas útiles para generar conocimiento sobre la lógica social que sustentó esa escenografía.

\section{AGRADECIMIENTOS}

A Jesús Bermejo, por habernos invitado a participar en el seminario Syntax Analysis, por su apoyo y comprensión en unos momentos difíciles. A Miguel Herrero y Beau Murphy, alumnos de la Universidad de New Mexico, sin la ayuda de los cuales habría sido imposible llevar a buen puerto el trabajo de campo. Esta investigación forma parte del proyecto Agriculture and 
Empire in the High Altitude Atacama, codirigido por Frances Hayashida (University of New Mexico), César Parcero-Oubiña (INCIPIT, CSIC), Andrés Troncoso (Universidad de Chile) y Diego Salazar (Universidad de Chile), y financiado por la National Science Foundation (Catalyzing New International Collaborations Grant OISE-1265816), la Wenner-Gren Foundation for Anthropological Research (International Collaborative Research Grant) y la National Geographic Society (Research and Exploration Grant 9296-13). La versión final de este artículo se benefició de la puesta en común que todo el equipo del proyecto llevamos a cabo en el Seminario Land, Water and Empire in the High-Altitude Atacama que tuvo lugar en la School for Advanced Research (Santa Fe, New Mexico) entre el 11 y 13 de abril de 2015.

\section{BIBLIOGRAFÍA}

Acuto, F. 2007: "Fragmentación v/s integración comunal: Repensando el período Tardío del Noroeste Argentino", Estudios Atacameños, 34, pp. 71-95.

Aldunate, C. y Castro, V. 1981: Las chullpas de Toconce y su relación con el poblamiento altiplánico en el Loa superior. Período Tardío. Ed. Kultrún, Santiago de Chile.

Aldunate, C., Berenguer, J. y Castro, V. 1982: "La función de las Chullpa en Likan”, en Actas del VIII Congreso de Arqueología de Chile Valdivia, pp. 129-74. Ed. Kultrún, Santiago de Chile.

Allison, P. (ed.) 1999: The Archaeology of Household activities. Routledge, London.

Arenas Esteban, J. A. 2007: "Sociedad, ideología y entornos construidos durante la protohistoria del oriente meseteño: El caso de El Ceremeño de Herrería", Trabajos de Prehistoria, 64(1), pp. 121-136.

Arkush, E. 2008: "War, Chronology and Causality in the Titicata Basin", Latin American Antiquity, 19(4), pp. 339-373.

Arkush, E. 2011: Hillforts of the Ancient Andes: Colla Warfare, Society and Landscape. University of Florida Press, Gainesville.

Ayán Vila, X. M. 2012a: "Una aproximación a la Arqueología de la Arquitectura castreña: experiencias desde Galicia”, en J. P. López y D. Hernández (eds.), Actas del II Congreso de Arqueología de Chamartín (Ávila). La Ergástula Ediciones, Madrid.

Ayán Vila, X. M. 2012b: Casa, familia y comunidad en la Edad del Hierro del NW. Tesis doctoral. Universidad de Santiago de Compostela, Santiago de Compostela.

Baker, G. H. 1994. Le Corbusier: análisis de la forma. Gustavo Gili, México.

Baker, G. H. 1998: Análisis de la forma: urbanismo y arquitectura. Gustavo Gili, México.

Barthes, R. 1986: "Semiology and the Urban", en M. Gottdiener y A. Lagopoulos (eds.), The City and the Sign, pp. 88-98. Columbia Univ. Press, New York.

Bender, B. (ed.). 1993: Landscape, Politics and Perpectives. Oxford: Berg.

Berenguer, J. 2004: Caravanas, interacción y cambio en el desierto de Atacama. Sirawi Ediciones, Santiago de Chile.

Berenguer J., Aldunate, C. y Castro, V. 1984: “Orientación orográfica de las chulpas en Likan: la importancia de los cerros en la fase Toconce", en B. Bitmann (ed.), Simposio Culturas Atacameñas, XLIV congreso Internacional de Americanistas, pp. 175-220. Instituto de Investigaciones Arqueológicas Le Paige, Universidad del Norte, Antofagasta.
Bermejo Tirado, J. 2009: "Leyendo los espacios: una aproximación crítica a la sintaxis espacial como herramienta de análisis arqueológico", Arqueología de la Arquitectura, 6, pp. 47-62.

Blanton, R. 1994: Houses and Households: A Comparative Study. New York: Plenum Press.

Bourdieu, P. 1997: Razones prácticas. Sobre la teoría de la acción. Anagrama, Barcelona.

Bourdieu, P. 2002: Outline of a Theoy of Practice. Cambridge University Press, Cambridge.

Bradley, B. A. 1993: "Planning, Growth, and Functional Differentiation at a Prehistoric Pueblo: A Case Study from SW Colorado", Journal of Field Archaeology, 20(1), pp. 23-42.

Brown, F. E. 1990a: "Comment on Chapman: some cautionary notes on the application of spatial measures to prehistoric settlements", en R. Samson (ed.), pp. 93-109.

Brown, F. E. 1990b: “Analysing Small Building Plans. A Morphological Approach", en Samson, R. (ed.), pp. 259-76.

Castro, V., Berenguer, J. y Aldunate, C.. 1979: “Antecedentes de una interacción altiplano - área atacameña durante el período tardío: Toconce", en Actas del VII congreso Nacional de Arqueología Chilena, Vol. 2, pp. 477-498. Editorial Kultrún, Santiago de Chile.

Castro, V., Aldunate, C. y Berenguer, J. 1984: "Orígenes altiplánicos de la Fase Toconce", Estudios Atacameños, 7, pp. 209-235

Castro, V. y Cornejo, L. E. 1990: "Estudios en el pukara de Turi. Norte de Chile”, Gaceta Arqueológica Andina, V, 17, pp. 57-66.

Castro, V.; Maldonado, F. y Vázquez, M. 1993: “Arquitectura del Pukara de Turi”, en Actas del XII Congreso Nacional de Arqueología Chilena, I, pp. 79-106. Temuco.

Castro, V. y Aldunate, C. 2003: "Sacred Mountains in the Highlands of the South-Central Andes", Mountain Resarch and Development, 23(1), pp. 73-79.

Chapman, J. 1990: "Social Inequality on Bulgarian Tells and the Varna Problem", en R. Samson (ed.), pp. 49-92.

Ching, F. 1995: Arquitectura: forma, espacio y orden. México: Gustavo Gili $\left[10^{\mathrm{a}}\right.$ ed.].

Clastres, P. 2001: Investigaciones en antropología política. Gedisa, Barcelona.

Clastres, P. 2010: La sociedad contra el Estado. Madrid: La Llevir-Virus.

Cobas Fernández, I. y Prieto Martínez, M. a P. 2001: "La cadena tecnológica operativa como una herramienta teórica y metodológica. Una perspectiva desde los planteamientos de la Arqueología del Paisaje", Cuadernos de Estudios Gallegos, 14, pp. 9-27.

Coben, L. S. 2006: "Other Cuzcos: replicated theaters of Inka power", en T. Inomata y L. S. Coben (eds.), Archaeology of Performance: Theaters of Power, Community, and Politics, pp. 223-60. Altamira Press, Berkeley.

Covey, A. 2008: "Multiregional perspectives in the Archaeology of the Andes during the Late Intermediate Period (c. AD. 1000-1400)", Journal of Archaeological Research, 16(3), pp. 287-338.

Criado Boado, F. 1993: "Visibilidad e interpretación del registro arqueológico", Trabajos de Prehistoria, 50, pp. 39- 56.

Criado Boado, F. 1999: Del Terreno al Espacio: Planteamientos y Perspectivas para la Arqueología del Paisaje. CAPA (Criterios y Convenciones en Arqueología del Paisaje), 6. Grupo de Investigación en Arqueoloxía da Paisaxe, Santiago de Compostela.

Dawson, P. C. 2002: "Space syntax analysis of Central Inuit snow houses", Journal of Anthropological Archaeology, 21, pp. 464-80.

De Certeau, M. 1984: The Practice of Everyday Life. University of California Press, Berkeley.

Eco, U. 1986: "Functionalism and Sign: The Semiotics of Architecture", en M. Gottdiener y A. Lagopoulos (eds), The City and the Sign, pp. 56-85. Columbia University Press, New York.

Eco, U. 1987: “How an Exposition Exposes Itself”, en U. Eco (ed.), Travels in Hyperreality, pp. 296-299. Pan Books, London.

Fernández Götz, M. A. 2008: La construcción arqueológica de la etnicidad, Serie Keltia, 42. Toxosoutos, Noia. 
Funari, P. y Zarankin, P. 2003: "A social archaeology of housing from a Latin American perspective", Journal of Social Archaeology, 3(1), pp. 23-45.

García Rodríguez, S. 2011: Análisis formal de la arquitectura doméstica del asentamiento de Topaín. Memoria Técnica depositada en el INCIPIT (CSIC). Santiago de Compostela.

Giddens, A. 1984: The constitution of society: outline of the theory of structuration. Polity Press: Cambridge.

González Ruibal, A.; Ayán Vila, X. M. y Falquina Aparicio, Á. 2009: "Deepmapping the gumuz house”, en X. Ayán, P. Mañana y R. Blanco (eds.), Archaeotecture: Second Floor, pp. 79-96. British Archaeological Reports International Series 1971. Archaeopress, Oxford.

González Ruibal, A., Ayán Vila, X. M. y Falquina Aparicio, Á. 2013: "Cultura material y etnicidad. Observaciones etnoarqueológicas en la región de Gambela (Etiopía)", Materialidades. Perspectivas en cultura material, 1, pp. 57-116.

Grahame, M. 2000: Reading Space: Social Interaction and Identity in the Houses of Roman Pompeii. A syntatical approach to the analysis and interpretation of built space. BAR International Series 886. Archaeopress, Oxford. Guidoni, E. 1989: Arquitectura primitiva. Aguilar, Madrid.

Hillier, B. 1973: "In defence of space". Royal Institute of British Architects Journal, november 1973, pp. 539-44.

Hillier, B. 1996: Space is the Machine. Cambridge University Press, Cambridge.

Hillier, B. y Hanson, J. 1984: The social logic of space. Cambridge University Press, Cambridge.

Hillier, B. y Leaman, A. 1974: "How is design possible?" Journal of Architectural and Planning Research, 3(1), pp. 4-11.

Hillier, B.; Burdett, R.; Peponis, J. y Penn, A. 1987: “Creating life: Or, Does Architecture Determine Anything? Architecture and Comportement/Architecture and Behaviour, 3(3), pp. 233-250.

Hillier, B. ; Hanson, J. y Peponis, J. 1987: „Syntactic Analysis of Settlements", Architecture and Comportement/ Architecture and Behaviour, 3(3), pp. 217-231.

Hodder, I. 1982: Symbolic and structural archaeology. Cambridge University Press, Cambridge.

Jiménez Ávila, J. 2005: "Cancho Roano: el proceso de privatización de un espacio ideológico”, Trabajos de Prehistoria, 62 (2), pp. 105-124.

Leach, E. 1976: Culture and Communication. The logic by which symbols are connected: an introduction to the use of structuralist analysis in social anthropology. Cambridge: Cambridge University Press.

Leibowicz, I. 2012: "Ideología y Espacio: Conquista Inca en la Quebrada de Humahuaca, Argentina”, Revista Chilena de Antropología, 25(1), pp. 65-91.

Lemonnier, P. 1986: "The study of material culture today: toward an anthropology of technical systems", Journal of Anthropological Archaeology, 5, pp. 147-86.

Lemmonier, P. 1991: Technological choices. Transformation in material cultures since the Neolithic. Ed. Routledge, London.

Maldonado, A. y Paredes, D. 2015: "Análisis de madrigueras fósiles y muestras de sedimento de las localidades de Topaín, Turi y Paniri”. Informe presentado en el NSF Team Seminar Land, Water, and Empire in the HighAltitude Atacama (SAR, Santa Fe, 11-13 de abril de 2015).

Mañana Borrazás, P., Blanco Rotea, R. y Ayán Vila, X. M. 2002: Arqueotectura 1: Bases Teórico-Metodológicas para una Arqueología de la Arquitectura. TAPA (Traballos en Arqueoloxía da Paisaxe), 25. Laboratorio de Arqueoloxía, (CSIC-XuGa), Santiago de Compostela.

Manríquez, V. 2015: "Sistemas y Prácticas agrícolas en Aiquina-Turi-Paniri. Una primera aproximación". Informe presentado en el NSF Team Seminar Land, Water, and Empire in the High-Altitude Atacama (SAR, Santa Fe, 11-13 de abril de 2015).

Manum, B.; Rusten, E. y Benze, P. 2005. "AGRAPH. Software for Drawing and Calculating Space Syntax Graphs", en A. Van Nees (ed.), Proceedings of the $5^{\text {th }}$ Space Syntax Symposium. June 2005, pp. 96-103. Techne Press, Amsterdam.

Márquez, J. E. 2003: "Recintos Prehistóricos atrincherados (RPA) en Andalucía (España): Una propuesta interpretativa”, en Jorge, S. O. (ed.): Recintos murados da Pré-história recente, pp. 269-284. Porto.

Mayer, E. 2002: The articulated Peasant. Household economies in the Andes. Westwiew Press.
Moore, H. L. 1986: Space, text and gender. An anthropological study of the Marakwet of Kenya. Cambridge University Press, Cambridge.

Moore, J. D., 1992: "Pattern and meaning in prehistoric Peruvian architecture: the architecture of social control in the Chimu state", Latin American Antiquity, 3, pp. 95-113.

Moore, J. D., 1996: "Archaeology of plazas and the proxemics of ritual: three Andean traditions", American Anthropologist, 98, pp. 789-802.

Murphy, B. 2015: "A Spatial Analysis of Surface Artifact Distributions at the Inka Administrative Site of Turi, Northern Chile". Póster presentado en el $80^{\text {th }}$ SAA Meeting (San Francisco, USA, Abril 2015).

Nielsen, N. 1998-1999: "Tráfico de caravanas en el sur de Bolivia: Observaciones etnográficas e implicancias arqueológicas", Relaciones de la Sociedad Argentina de Antropología, 22/23, pp. 139-178.

Nielsen, A. 2002: "Asentamientos, conflicto y cambio social en el altiplano de Lípez”. Revista Española de Antropología Americana, 32, pp. 179-205.

Nielsen, A. 2006a: "Pobres jefes: Aspectos corporativos en las formaciones sociales pre-incaicas de los Andes circumpuneños", en Gnecco, C. y Lagebaek, C. H. (eds.), Contra la tiranía Tipológica en Arqueología: Una visión desde Sudamérica, pp. 121-50. Universidad de Los Andes, Bogotá.

Nielsen, A. 2006b: "Plaza para los antepasados: Descentralización y poder corporativo en las formaciones políticas preincaicas de los Andes circumpuneños", Estudios Atacameños, 31, pp. 63-89.

Nielsen, A. 2009: "Ancestors at war: meaningful conflict and social process in the South Andes", en Nielsen, A. y Walker, W. (eds.), Warfare in Cultural Context: Practice, Agency and the Archaeology of Violence, pp. 218-43. University of Arizona Press, Tucson.

Parcero Oubiña, C.; Fábrega Álvarez, P.; García Rodríguez, S.; Troncoso Meléndez, A y Salazar Sutil, D. 2012: "Paisajes fortificados y agrarios en el altiplano andino. Aproximaciones al pukara de Topaín”, Informes $y$ Trabajos del IPC, 7, pp. 22-39.

Parcero Oubiña, C.; Fábrega Álvarez, P.; Ferro, C.; Troncoso Meléndez, A y Salazar Sutil, D. 2013: "Trabajos en torno al pukara de Topaín (segunda región, Chile). Campaña de 2011", Informes y Trabajos del IPCE, 9, pp. 58-85.

Parcero Oubiña, C.; Fábrega Álvarez, P.; Ferro Vázquez, C.; Troncoso Meléndez, A., Salazar Sutil, D. y Hayashida, F. 2014: "Paisajes fortificados en el altiplano andino: nuevos trabajos en torno al Pukara de Topaín (segunda región, Chile)", Informes y Trabajos, 11. Excavaciones en el exterior 2012, pp. 127-44.

Parcero Oubiña, C. y Fábrega Álvarez, P. 2015: "Dataciones radiocarbónicas". Informe presentado en el NSF Team Seminar Land, Water, and Empire in the High-Altitude Atacama (SAR, Santa Fe, 11-13 de abril de 2015).

Parker Pearson, M. y Richards, C. (eds). 1994a: Architecture and Order. Approaches to Social Space. Routledge: London.

Parker Pearson, M. y Richards, S. C. 1994b: "Ordering the world: perceptions of Architecture, Space and Time”, en Parker Pearson, M. y Richards, C. (eds.), pp. 1-37.

Pimentel, G. 2003: "Identidades y Arqueología", Revista Werken, 4, pp. 75-86.

Pimentel, G. 2008: "Evidencias Formativas en una vía interregional con conexiones entre San Pedro de Atacama y el Altiplano de Lípez", Estudios Atacameños, 35, pp. 7-33.

Pimentel, G. 2009: "Las Huacas del tráfico. Arquitectura ceremonial en rutas prehispánicas del desierto de Atacama". Boletín del Museo Chileno de Arte precolombino, 14, pp. 9-38.

Pollard, G. 1970: The Cultural Ecology of Ceramic Stage Settlement in the Atacama Desert. Ph.D. Dissertation. Columbia University, New York.

Preucel, R. W. 2006: Archaeological Semiotics. Blackwell, Oxford.

Prieto Montt, M. y Ayán Vila, X. M. 2014: 'Although the Loneliness is great, greater is the Love of my Country'. Archaeology of a Military Outpost on the Topaín Hillock (Antofagasta Region, Chile), Journal of Contemporary Archaeology, 1(2), pp. 323-350.

Rapoport, A. 1972: Vivienda y cultura. Gustavo Gili, Barcelona.

Rivolta, M. ${ }^{a}$ C. 2011: "Lo simbólico y lo cotidiano: el uso del concepto de unidad doméstica en arqueología andina”, en P. Ayala y F. Vilches (eds.), Teoría arqueológica en Chile. Reflexionando en torno a nuestro quehacer disciplinario, pp. 229-244. Universidad de Chile, Universidad Católica del Norte, Santiago de Chile. 
Sahlins, M. 1972: Las sociedades tribales. Labor, Barcelona.

Salazar Sutil, D. 2013: Poblamiento preincaico e incaico en el Loa superior. Seminario impartido en Chiu-Chiu el 7 de julio de 2013.

Samson, R. (ed.) 1990: The social Archaeology of houses. Edinburgh University Press, Edinburgh.

Sánchez, J. 1998: "La Arqueología de la Arquitectura. Aplicación de nuevos modelos de análisis a estructuras de la Alta Andalucía en época ibérica", Trabajos de Prehistoria, 55, 2, pp. 89-109.

Shapiro, J. S., 1999: "New light on old adobe: a space syntax analysis of the Casa Grande", Kiva 64, pp. 419-46.

Sinclaire, C., 1994: "Los sitios de "muros y cajas" del río Loa y su relación con el tráfico de caravanas", en Albeck, M. E. (ed.), Taller de Costa a Selva, pp. 51-76. Instituto Interdisciplinario Tilcara, Universidad de Buenos Aires, Buenos Aires.

Tecklin, D.; Bauer, C. y Prieto, M. 2013: "Making environmental law for the market: the emergence, character, and implications of Chile's environmental regime", Environmental Politics, 20:6, pp. 879-98.

Thomas, J. 2001: "Archaeologies of Place and Landscape", en I. Hodder (ed.), Archaeological Theory Today, pp. 165-186. Polity Press: Cambridge.

Troncoso Meléndez, A. 2015: Contextualizando procesos: una aproximación al periodo intermedio tardio y tardio en los Andes del Sur. Informe presentado en el NSF Team Seminar Land, Water, and Empire in the High-Altitude Atacama (SAR, Santa Fe, 11-13 de abril de 2015).

Urbina Araya, S. 2007: "Estudio arquitectónico del Pucara de Topaín (río Salado, Norte de Chile)", Boletín de la Sociedad Chilena de Arqueología, 40, pp. 29-46.

Urbina Araya, S. 2010: “Asentamiento y Arquitectura: Historia prehispánica tardía de las quebradas altas del río Loa (900-1540 DC)”, en Actas del XVII Congreso Nacional de Arqueología Chilena, Tomo I, pp. 119-131, Valdivia.

Van Dyke, R. M. 1999: "Space syntax analysis at the chacoan outlier of Guadalupe". American Antiquity, 64(3), pp. 461-73.

Wernke, S. A. 2012: "Spatial network analysis of a terminal prehispanic and early colonial settlement in highland Peru", Journal of Archaeological Science, 39, pp. 1111-1122.

Wilk, R. y Rathje, W. 1982: "Household Archaeology", American Behavioral Scientist, 25(6), pp. 617-39.

Yaeger, J. y Canuto, M. A. 2000a: The Archaeology of Communities. A new World Perspective. Routledge: London and New York.

Yaeger, J. y Canuto, M. A. 2000b: "Introducing an archaeology of communities", en J. Yaeger y M. A. Canuto (eds.), pp. 1-15.

\section{ANEXO}

Hemos empleado el programa AGRAPH (Manum, Rusten y Benze 2005) para elaborar los mapas de accesibilidad y el cálculo de relaciones espaciales. Los índices numéricos manejados para cada estancia son $T D$ (profundidad total), $M D$ (profundidad específica), $R A$ (asimetría relativa), $i$ (valor de integración) y $C V$ (control de valor). Aquellas estructuras que tengan un índice CV más elevado ejercen dominio y control sobre el espacio, a diferencia de las que poseen índices bajos. Mientras un bajo valor de RA indica una alta integración espacial, es un alto valor de $i$ el que indica también una alta integración espacial. Como se puede apreciar, los deflectores y recibidores son esenciales en el control de la permeabilidad de los espacios.

Vivienda tipo. Estructura 10S017. Sector A [Fig. 9].

\begin{tabular}{|l|c|c|c|c|c|}
\hline $\mathbf{N}^{\mathbf{0}}$ unidad espacial & TD & MD & RA & i & CV \\
\hline Entrada & 6 & 2,00 & 1,00 & 1,00 & 0,50 \\
\hline Recibidor & 4 & 1,33 & 0,33 & 3,00 & 1,50 \\
\hline Deflector & 4 & 1,33 & 0,33 & 3,00 & 1,50 \\
\hline Interior & 6 & 2,00 & 1,00 & 1,00 & 0,50 \\
\hline Mínima & 4,00 & 1,33 & 0,33 & 1,00 & 0,50 \\
\hline Media & $\mathbf{5 , 0 0}$ & $\mathbf{1 , 6 6}$ & $\mathbf{0 , 6 6}$ & $\mathbf{2 , 0 0}$ & $\mathbf{1 , 0 0}$ \\
\hline Máxima & 6,00 & 2,00 & 1,00 & 3,00 & 1,50 \\
\hline
\end{tabular}

Sector B2 (Casa compleja)

\begin{tabular}{|l|c|c|c|c|c|}
\hline $\mathbf{N}^{\mathbf{0}}$ unidad espacial & TD & MD & RA & i & CV \\
\hline exterior & 48 & 4,36 & 0,67 & 1,48 & 1,00 \\
\hline 74 & 56 & 5,09 & 0,81 & 1,22 & 1,50 \\
\hline 65 & 66 & 6,00 & 1,00 & 1,00 & 0,50 \\
\hline 81 & 42 & 3,81 & 0,56 & 1,77 & 1,00 \\
\hline 79 & 38 & 3.45 & 0,49 & 2,03 & 1,00 \\
\hline Recibidor & 36 & 3,27 & 0,45 & 2,20 & 1,00 \\
\hline Deflector & 36 & 3,27 & 0,45 & 2,20 & 1,00 \\
\hline 71 & 42 & 3,81 & 0,56 & 1,77 & 1,00 \\
\hline 68 & 48 & 4,36 & 0,67 & 1,48 & 1,00 \\
\hline 62 & 56 & 5,09 & 0,81 & 1,22 & 1,00 \\
\hline 63 & 66 & 6,00 & 1,00 & 1,00 & 0,50 \\
\hline
\end{tabular}


Sector B2 (Casa compleja) (cont.)

\begin{tabular}{|l|c|c|c|c|c|}
\hline $\mathbf{N}^{\mathbf{0}}$ unidad espacial & TD & MD & RA & i & CV \\
\hline 70 & 38 & 3,45 & 0,49 & 2,03 & 1,00 \\
\hline Mínima & 36,00 & 3,27 & 0,45 & 1,00 & 0,50 \\
\hline Media & $\mathbf{4 7 , 6 6}$ & $\mathbf{4 , 3 3}$ & $\mathbf{0 , 6 6}$ & $\mathbf{1 , 6 1}$ & $\mathbf{1 , 0 0}$ \\
\hline Máxima & 66,00 & 6,00 & 1,00 & 2,20 & 1,50 \\
\hline
\end{tabular}

Sector A3

\begin{tabular}{|l|c|c|c|c|c|}
\hline $\mathbf{N}^{\mathbf{0}}$ unidad espacial & TD & MD & RA & i & CV \\
\hline Exterior (3) & 9 & 1,50 & 0,20 & 5,00 & 3,00 \\
\hline 19 & 14 & 2,33 & 0,53 & 1,87 & 0,25 \\
\hline 18 & 10 & 1,66 & 0,26 & 3,75 & 0,58 \\
\hline 12 & 14 & 2,33 & 0,53 & 1,87 & 0,25 \\
\hline 13 & 11 & 1,83 & 0,33 & 3,00 & 2,00 \\
\hline Exterior 2 & 16 & 2,66 & 0,66 & 1,50 & 0,33 \\
\hline $6 a$ & 10 & 1,66 & 0,26 & 3,75 & 0,58 \\
\hline Mínima & 9,00 & 1,50 & 0,20 & 1,50 & 0,25 \\
\hline Media & $\mathbf{1 2 , 0 0}$ & $\mathbf{2 , 0 0}$ & $\mathbf{0 , 4 0}$ & $\mathbf{2 , 9 6}$ & $\mathbf{1 , 0 0}$ \\
\hline Máxima & 16,00 & 2,66 & 0,66 & 5,00 & 3,00 \\
\hline
\end{tabular}

Sector A2

\begin{tabular}{|l|c|c|c|c|c|}
\hline $\mathbf{N}^{\mathbf{0}}$ unidad espacial & TD & MD & RA & i & CV \\
\hline exterior & 14 & 1,75 & 0,21 & 4,66 & 4,50 \\
\hline 21 & 21 & 2,62 & 0,46 & 2,15 & 0,20 \\
\hline 3 & 21 & 2,62 & 0,46 & 2,15 & 0,20 \\
\hline 0 & 15 & 1,87 & 0,25 & 4,00 & 0,70 \\
\hline 20 & 21 & 2,62 & 0,46 & 2,15 & 0,20 \\
\hline 24 & 21 & 2,62 & 0,46 & 2,15 & 0,20 \\
\hline recibidor & 18 & 2,25 & 0,35 & 2,80 & 1,00 \\
\hline deflector & 23 & 2,87 & 0,53 & 1,86 & 1,50 \\
\hline 8 & 30 & 3,75 & 0,78 & 1,27 & 0,50 \\
\hline Mínima & 14,00 & 1,75 & 0,21 & 1,27 & 0,20 \\
\hline Media & $\mathbf{2 0 , 4 4}$ & $\mathbf{2 , 5 5}$ & $\mathbf{0 , 4 4}$ & $\mathbf{2 , 5 8}$ & $\mathbf{1 , 0 0}$ \\
\hline Máxima & 30,00 & 3,75 & 0,78 & 4,66 & 4,50 \\
\hline
\end{tabular}

Sector A1

\begin{tabular}{|l|c|c|c|c|c|}
\hline $\mathbf{N}^{\mathbf{0}}$ unidad espacial & TD & MD & RA & i & CV \\
\hline exterior & 8 & 1,60 & 0,30 & 3,33 & 2,50 \\
\hline 21 & 12 & 2,40 & 0,70 & 1,42 & 0,33 \\
\hline 14 & 12 & 2,40 & 0,70 & 1,42 & 0,33 \\
\hline 10 & 8 & 1,60 & 0,30 & 3,33 & 0,83 \\
\hline 15 & 10 & 2,00 & 0,50 & 2,00 & 1,50 \\
\hline 11 & 14 & 2,80 & 0,90 & 1,11 & 0,50 \\
\hline Mínima & 8,00 & 1,60 & 0,30 & 1,11 & 0,33 \\
\hline Media & $\mathbf{1 0 , 6 6}$ & $\mathbf{2 , 1 3}$ & $\mathbf{0 , 5 6}$ & $\mathbf{2 , 1 0}$ & $\mathbf{1 , 0 0}$ \\
\hline Máxima & 14,00 & 2,80 & 0,90 & 3,33 & 2,50 \\
\hline
\end{tabular}

